\title{
5. Subjektivistische Theorien der Farben
}

Die Grundidee des Subjektivismus ist es, daß Farbtatsachen nur geistabhängig existieren können. Er inpliziert somit die epistemische Notwendigkeit des Bikonditionals (BK). Farbtatsachen müssen demnach logisch mit den entsprechenden, über ihre Phänomenalität individuierten Farbwahrnehmungen verbunden sein. Sonst kann die Geistesabhängigkeit ersterer vor dem Hintergrund eines globalen ontologischen Realismus nicht gewährleistet werden. Eine apriorische Beziehung zwischen zwei Entitäten kann nur dann bestehen, wenn die eine über die andere individuiert oder definiert wird: Farben sind demnach per definitionem diejenigen Eigenschaften, die in Farbwahrnehmungen präsentiert werden. Die einzig sinnvolle Möglichkeit, Farbtatsachen auf diese Art und Weise mit phänomenal charakterisierten Sinneserfahrungen zusammenzubringen, ist es, Farben selbst eine Phänomenalität zuzusprechen. Die Inviduationsthese (IND) findet also für den Subjektivisten ihre Ausformung in der These ( $\left.\mathrm{IND}_{\mathrm{P}}\right)$ : Farben sind die in Farbwahrnehmungen phänomenal präsentierten Eigenschaften. Die Natur der Farben wird (mindestens) mithilfe der These (PHE) analysiert werden. Der Subjektivismus fordert demgemäß eine phänomenale Veridizität: die Merkmale des phänomenalen Aspektes der Intuitiven Farbkonzeption treffen auf Farben zu. Farben zeigen somit die Eigenschaften zweiter Ordnung, die üblicherweise mit dem phänomenalen Charakter von Farbwahrnehmungen assoziiert werden. In diesem Sinne drückt die These (PHE) keine genuine, ontologische Transparenz aus, wie es etwa die Transparenzthese des Objektivismus ${ }_{\mathrm{NEC}}$ tut.

Die Aussage, daß Farben mit Farbwahrnehmungen a priori verknüpft sind, genügt allein jedoch noch nicht. Zusätzlich muß noch die ontologisch fundierte, definitorische Priorität angegeben werden: entweder werden Farbtatsachen über die entsprechenden Farbwahrnehmungen analysiert, oder, umgekehrt, die Farbwahrnehmungen über die entsprechenden Farbtatsachen. ${ }^{1}$ Eine zirkuläre Analyse muß dabei natürlich vermieden werden,

1 Peacocke (1984) diskutiert ebenfalls eine ähnliche, wenn auch verschiedene - da semantisch, und nicht ontologisch, orientierte - definitorische Priorität: ob der Begriff Rot-zu-sein (being red) durch den einen oder anderen Wahrnehmungsbegriff - wie Rot-zu-erscheinen (looking red) oder Im-Gesichtsfeld-als-Rot-Präsentiert-zu-werden (being red') - analysiert werden muß, oder umgekehrt. Insbeson- 
will man sich über die zugrundeliegende Ontologie der Farben klar werden. ${ }^{2}$ Es kann also nicht angehen, daß beide - oder keine - Entitätsarten gegenüber der anderen definitorische Priorität genießen. Stattdessen muß es möglich sein, entweder die Farbtatsachen oder die phänomenalen Farbwahrnehmungstypen unabhängig von den jeweiligen, anderen Entitäten definieren zu können. Werden die Farbeigenschaften über die Farbwahrnehmungen bestimmt, dann müssen letztere mithilfe von

dere bespricht Peacocke noch eine dritte Alternative, derzufolge weder Rot-zusein, noch der fragliche Wahrnehmungsbegriff Priorität genießen, sondern beide gleichermaßen durch einen dritten Begriff definiert werden. Dabei kommt er jedoch zu dem Resultat, daß diese Möglichkeit sich letztenendes auf die von ihm favorisierte Priorität der Wahrnehmungsbegriffe reduzieren muß (vgl. Peacocke (1984): 411f.; 413). Nun werden die meisten seiner Überlegungen auch für die ontologische Ebene Gültigkeit besitzen. Doch eine Eins-zu-Eins-Abbildung beider Diskussionsebenen ist nicht immer möglich, da sich - je nach Farbtheorie - jeder der drei oben erwähnten Begriffe auf Farbeigenschaften beziehen kann.

2 Gerade dem subjektivistischen Dispositionalismus ist oftmals der Zirkularitätsvorwurf gemacht worden, daß sowohl Farbtatsachen über Farbwahrnehmungen als auch Farbwahrnehmungen über Farbtatsachen definiert werden (vgl. Boghossian \& Velleman (1989): 88f.; Einleitung zu Byrne \& Hilbert (1997a): xxi; Peacocke (1984): 415). Diese wechselseitige Bestimmung ist zwar informativ (sie behauptet den engen Zusammenhang beider Entitätsarten), aber sie ist ebenso trivial - sehr ähnlich den dispositionalen Erklärungen, denen zufolge eine Manifestation nicht durch eine Disposition erklärt werden kann, weil diese selbst über die Manifestation definiert ist. Nun ist es den Farbdispositionalisten durchaus möglich, die Zirkularität zu akzeptieren, wenn sie keine reduktive Analyse der Farben im Sinn haben (vgl. McGinn (1983): 7f.; Broackes (1992): 442; Einleitung zu Byrne \& Hilbert (1997a): xxi). Da dies hier jedoch das erklärte Ziel ist, sollte die dispositionale These dadurch Substantialität erhalten, daß eine der beiden Entitätsarten unabhängig von der anderen spezifiziert wird (wie auch dispositionale Gesetze durch die Einbeziehung der kausalen Ebene erklärend werden können). Darüberhinaus geben Boghossian und Velleman ein überzeugendes Argument dafür, daß es sich hier um eine viziöse Zirkularität handelt (vgl. Boghossian \& Velleman (1989): 89ff.):

„The dispositionalist about colour not only invokes the content of colour experience in explicating that content; he places that content in a relation to itself that is impossible for it to occupy. For his explication says that the content of the visual experience of red must contain, as a proper part, the content of the visual experience of red. To see something as red... is to have 
phänomenalen Eigenschaften individuiert werden können, die von den Farben verschieden sind: hierbei wird es sich wohl um Farbqualia handeln. Charakterisieren dagegen die Farben die Farbwahrnehmungen, müssen die Farben mit den die Wahrnehmungstypen individuierenden, phänomenalen Eigenschaften gleichgesetzt werden: also entweder mit den Farbqualia selbst oder mit anderen, in Farbwahrnehmungen präsentierten, subjektiven Eigenschaften. ${ }^{3}$

Die subjektivistischen Farbtheorien lassen sich dementsprechend ganz grob in zwei Kategorien einteilen. Der Projektivismus analysiert die farbphänomenalen Wahrnehmungen über die in ihnen phänomenal präsentierten Farben, während die relationalistischen Theorien (einschließlich des Dispositionalismus) hingegen die Farben mithilfe der über ihre Qualia individuierten Farbwahrnehmungen definieren. Die genauen Ausformungen dieser Abhängigkeiten sollen in den folgenden Abschnitten erläutert werden. In beiden Fällen werden jedoch die Sinneserfahrungen nicht über ihren Gehalt, sondern über ihre Phänomenalität bestimmt; und auch die Farbeigenschaften selbst erhalten ihre Charakterisierung aufgrund dieser uns introspektiv zugänglichen Phänomenalität, so daß die Apriorizität des Bikonditionals gesichert ist. Die Analysethese (ANA) wird dabei von den Subjektivisten nicht mehr nur als metaphysische, sondern sogar als epistemische Notwendigkeit verstanden. Es kann zudem generell die Möglichkeit der Naturalisierung der phänomenalen Farben angenommen werden daß sie also entweder auf Eigenschaften von cerebralen oder auf Eigenschaften von mentalen Zuständen zurückgeführt werden können (unter der Voraussetzung, daß die Phänomenalität mentaler Zustände eine naturalistische Beschreibung erhalten kann) -, obwohl dieser Punkt auf den weiteren Verlauf der Argumentation keinen Einfluß haben wird. Schließlich ist eine systematische Veridizität für subjektivistische Theorie der Farben nicht mehr möglich, da bereits die Objektivität der Farbtatsachen von Beginn an

an experience whose content is that the thing is disposed to produce visual experiences with the content that it is red. The experiential content that something is red is thus embedded within itself, and this is a reflexive relation that no determinate content can occupy." (Boghossian \& Velleman (1989): 89f.)

3 Der Objektivismus zeigt ebenso diese zweite Form der Priorität, wobei für ihn die repräsentierten, objektiven Farben diese Individuationsrolle übernehmen. 
geleugnet wird.

\subsection{Die Repräsentierbarkeit von subjektiven Eigen- schaften}

Bevor nun die einzelnen Positionen genauer betrachtet werden sollen, lohnt es sich, bereits jetzt kurz auf einige, allgemeine Konsequenzen oder Schwierigkeiten für den Subjektivismus hinzuweisen und zudem die mit diesen zusammenhängende, generelle Überlegung anzustellen, ob ein Subjektivismus überhaupt zusätzlich davon ausgehen kann, daß Farben auch repräsentierte Eigenschaften sind. Zuerst einmal postuliert diese Position eine Disanalogie zwischen Formen und Farben. Sekundäre Qualitäten sind demnach ontologisch deutlich von primären Qualitäten verschieden, obwohl uns dieser Unterschied in unseren Sinneserfahrungen nicht unmittelbar gegeben ist. Diese Differenz hat unter anderem auch zur Folge, daß unsere Zuschreibungen von Farbeigenschaften nicht durch Tatsachen über die wahrgenommenen Objekte in der Welt, sondern durch Tatsachen über die wahrnehmenden Subjekte wahrgemacht werden. Daraus folgt aber, daß Farben nur noch eine indirekte Rolle in der Diskrimination und Wiedererkennung von Gegenständen in der Welt sowie für die Erklärung des Phänomens der Farbkonstanz spielen, weil sie nur als epistemische Vermittler für die Erkennung von Unterschieden in den objektiven Ursachen unserer Farbwahrnehmungen (also in den Reflektanzeigenschaften) dienen, selbst aber nicht zu den erkannten, objektiven Differenzen beitragen.

Um dieser letzten Konsequenz aus dem Weg gehen zu können, behaupten die meisten Subjektivisten, daß die Farben, auch wenn sie keine objektiven Eigenschaften der Gegenstände in der Welt sind, trotzdem noch von unseren Sinneserfahrungen als solche Eigenschaften repräsentiert werden. Dann kann in gewissem Sinne davon gesprochen werden, daß die Objekte aufgrund ,ihrer“" Farbigkeit diskriminiert und individuiert werden können. Solche Tendenzen finden sich verständlicherweise bei den Relationisten oder Dispositionalisten, die ja davon ausgehen, daß Farben von den Gegenständen selbst instantiierte Eigenschaften sind (vgl. etwa McGinn (1983): 1f.; 7). Insbesondere Johnston scheint dieser Ansicht zu sein, da er Farbdis- 
positionen sowohl als erklärende Ursachen für Farbwahrnehmungen unter Normalbedingungen annimmt (vgl. Johnston (1992): 138; 148) als auch ihnen die Fähigkeit zuschreibt, mittels ihres Wahrgenommenwerdens Farburteile rechtfertigen zu können (vgl. Johnston (1992): 138; 154). Letzteres bedingt, daß die entsprechenden Farbdispositionen von den Sinneserfahrungen repräsentiert werden; ersteres impliziert dies sogar, da es eine nomologische Korrelation unter Normalbedingungen formuliert. Diese Idee der Repräsentiertheit der subjektiven Farben ist aber auch bei den Projektivisten zu entdecken (vgl. Boghossian \& Velleman (1989). Einige subjektivistische Positionen können sogar so stark gelesen werden, daß sie den Wahrnehmungen nur diesen Farbgehalt zuerkennen (so wenigstens wird die Theorie von Boghossian und Velleman durch Shoemaker (1990) interpretiert: 115).

Unklarheiten hierüber entstehen vor allem dadurch, daß die betreffenden Farbsubjektivismen gar nicht auf die Frage eingehen, ob zusätzlich zu den Farben auch noch bestimmte objektive Charakteristika repräsentiert werden. Doch die Bejahung dieser Frage ist wohl aus zwei Gründen unumgänglich. Erstens kann mithilfe der Colorimetrie eine nomologische Korrelation unter Normalbedingungen zwischen Reflektanztypen $S S R_{\mathrm{T}}$ und phänomenalen Wahrnehmungstypen nachgewiesen werden. Aus der externalistischen Gehaltstheorie ergibt sich damit bereits, daß diese objektiven Eigenschaften von den fraglichen Sinneserfahrungen repräsentiert werden. Und zweitens könnten wir ohne solch eine Repräsentation objektiver Merkmale gar nicht in der Lage sein, mithilfe unserer Farbwahrnehmungen Gegenstände in der Welt objektiv zu differenzieren. Denn wenn allein geistabhängige Eigenschaften repräsentiert würden, bestände kein Grund dafür, daß die subjektiv festgestellten Unterschiede sich so auch in der Wirklichkeit finden würden. Dies ist zwar für sich genommen noch nicht problematisch (im Falle anderer Klassen von Eigenschaften, wie etwa ästhetischer, mag es vielleicht sogar die Regel sein); aber hinsichtlich der Farbigkeit der Welt scheint doch eine ausgesprochene Intersubjektivität und Übereinstimmung in den Farburteilen vorzuliegen. Unsere Farbwahrnehmungen haben doch gerade die Funktion, objektive Charakteristika in der Welt zu erkennen und anhand dieser Gegenstände zu diskriminieren. Somit wird es den Subjektivisten nicht möglich sein, diesen Sinneserfahrungen einen aus geistunabhängigen Reflektanzeigenschaften bestehenden Gehalt 
zuzugestehen.

Ob die Tendenzen, darüberhinaus noch einen zweiten Farbgehalt anzunehmen, eine Berechtigung haben, ist jedoch eine ganz andere Frage. In den Abschnitten über den repräsentationalen Aspekt sowie über die Unterscheidung von Objektivismus und Subjektivismus ist die These vertreten worden, daß (abgesehen vielleicht von dispositionalistischen Theorien) Eigenschaften notwendigerweise nur dann repräsentiert werden können, wenn sie ontologisch unabhängig von den betreffenden mentalen Zuständen sind. Begründet wurde dies hauptsächlich durch den Hinweis auf die dem Direkten Realismus zugrundeliegende Objektivitätsthese (OT). Im folgenden soll dieses Argument am Beispiel der Farben erläutert werden. Die zu überprüfende Hypothese lautet dementsprechend: Farben werden nicht von unseren Farbwahrnehmungen repräsentiert, wenn sie von diesen ontologisch abhängen. Es ist nun sinnvoll, von der allgemeinen Bestimmung der subjektivistischen Position auszugehen, derzufolge die mit den Farben zu identifizierenden Eigenschaften $P$ in den Farbwahrnehmungen phänomenal präsentiert sind und zudem einen subjektiven Charakter aufweisen. Damit diese $P$-Eigenschaften repräsentiert werden können, müssen sie einerseits zu den $P$-Wahrnehmungen in einer nomologischen Korrelation unter Normalbedingungen stehen und dürfen andererseits nicht von diesen Sinneserfahrungen selbst instantiiert werden.

Vor diesem Hintergrund kann die genannte Hypothese durch zwei Hauptargumente gestützt werden: (a) bei der Präsentationsrelation zwischen den fraglichen Sinneserfahrungen und den P-Eigenschaften handelt es sich weder um eine Repräsentation, noch um eine Detektion; (b) ein zweiter Gehalt - oder eine zweite, repräsentierte Eigenschaft - ist vollkommen überflüssig, da er hinsichtlich des Auftretens der betreffenden Wahrnehmungen keinerlei erklärende Rolle aufweist. Das zweite Argument hängt natürlich eng mit dem Merkmal der Erklärungskraft zusammen, welches ein Bestandteil des repräsentationalen Aspektes ist. Da eine solche Erklärungskraft automatisch gegeben ist, wenn eine Repräsentationsrelation vorliegt, kann ihre Abwesenheit auch als ein Indiz für das Nichtvorhandensein einer Repräsentation gedeutet werden. Das erste Argument wird sich vor allem an der Objektivitätsthese (OT) und der Aktualismusthese (AT) orientieren. Es wird sich zeigen, daß auf die Eigenschaften $P$ nur eine Vari- 
ante der letzteren These zutrifft, da es vor allem nicht möglich sein wird, hinsichtlich der Präsentation dieser Eigenschaften von einer Fehlermöglichkeit zu sprechen: was sich unter anderem auch in der Unmöglichkeit widerspiegeln wird, Normalbedingungen $\mathrm{zu}$ formulieren. Für beide Argumentationen wird es dabei von besonderer Wichtigkeit sein, daß entweder die Farbeigenschaften $P$ über die entsprechenden Farbwahrnehmungen $W_{\mathrm{P}}$ oder, umgekehrt, die Wahrnehmungen $W_{\mathrm{P}}$ über die Farben $P$ begrifflich definiert werden.

Beginnen wir mit den Überlegungen, die die - wichtigere - These (a) unterstützen, wobei in diesem Abschnitt allein die Repräsentationalität besprochen werden soll. Eine erste Vermutung könnte sein, daß die epistemische Notwendigkeit des Bikonditionals (BK) im Grunde keine anderen Möglichkeit offen läßt, als zu folgern, daß eine Farbtatsache immer nur zusammen mit einer Farbwahrnehmung auftreten kann, und umgekehrt: $P(x)$ $\leftrightarrow W_{\mathrm{P}}$. Doch dem kann der Subjektivist erwidern, daß es besondere Relation zwischen Eigenschaften und mentalen Zuständen gibt, die eine begriffliche Definition der einen über die anderen erlaubt, ohne diese starke, ontologische Koexistenz zu verlangen: und zwar die Repräsentationsrelation. Auch wenn $\mathrm{W}_{\mathrm{P}}$ die Eigenschaft $P$ repräsentiert, dann heißt dies nicht unbedingt, daß auch immer eine entsprechende $P$-Tatsache vorliegt: Fehlrepräsentationen sind prinzipiell möglich. Doch die vom Subjektivismus behauptete ontologische Abhängigkeit der als Farben verstandenen $P$-Eigenschaften von den Farbwahrnehmungen erlaubt die Mögichkeit solcher Fehler nicht. Zuerst einmal handelt es sich dabei um subjektive Eigenschaften. Folglich gilt die Objektivitätsthese (OT), die die Objektivität der repräsentierten Eigenschaften fordert, für diese nicht. Damit ist es nicht möglich, daß $P$-Tatsachen auftreten, ohne daß eine $P$-Wahrnehmung vorliegt: $P(x)$ $\rightarrow W_{\mathrm{P}}$. Damit wird die Grundintuition für den Direkten Realismus von den Farbeigenschaften verletzt. Doch diese Konsequenz kann der Subjektivismus noch akzeptieren, da sie ja nicht ausschließt, daß in den meisten Fällen doch von den repräsentierenden Zuständen unabhängige, objektive Eigenschaften repräsentiert werden.

Erst die Gegenrichtung ist entscheidend. Damit Repräsentation möglich ist, darf es nicht passieren, daß das Auftreten einer Farbwahrnehmung auch immer die Existenz einer Farbtatsache impliziert. Nun sind die Eigenschaften $P$ für den Subjektivisten die in Farbwahrnehmungen phänomenal prä- 
sentierten Eigenschaften. Folgt man nun der durch die These (AT**) interpretierten Aktualismusintuition, dann werden nicht nur in jeder Farbwahrnehmung solche Eigenschaften präsentiert, sondern sie sind zudem immer auch intern instantiiert: $W_{\mathrm{P}} \rightarrow P(x)$. Die resultierende Position ist eine direkt-realistische Spielart der Sinnesdatentheorie, die eben nicht eine Repräsentationsrelation annimmt, sondern von einer besonderen Präsentationsrelation ausgeht, die aus einer wechselseitigen, ontologischen Abhängigkeit besteht (dies drückt gerade die für den Subjektivismus relevante Aktualismusthese (AT**) aus). Es ist notwendig, daß jede Farbwahrnehmung von einer internen Farbtatsache begleitet wird, und umgekehrt: $W_{\mathrm{P}} \leftrightarrow P(x)$. Wenn demnach $\mathrm{W}_{\mathrm{P}}$ wirklich über das Vorkommen von $\mathrm{P}$ informieren sollte, kann es dabei niemals zu einem Fehler kommen, so daß eine Repräsentation ausgeschlossen ist. Dies ist zum Beispiel dann der Fall, wenn Farben als phänomenale Eigenschaften der Sinneserfahrungen selbst angesehen werden: wenn also subjektive Farben und (selbstverständlich nicht allein über den objektiven Reflektanzgehalt bestimmbare) Farbqualia gleichgesetzt werden.

Akzeptiert der Subjektivismus die Aktualismusthese (AT**) für die phänomenal präsentierten Eigenschaften, folgt also automatisch, daß diese nicht repräsentiert werden können. ${ }^{4}$ Der Subjektivismus muß demnach, will er die Repräsentiertheit der phänomenal präsentierten Farben retten, die Gültigkeit der Aktualismusthese für diese ablehnen. Zusätzlich darf er natürlich die Eigenschaften auch nicht als Eigenschaften der Wahrnehmungen selbst ansehen (auch deswegen können Farben, als Farbqualia verstanden, nicht repräsentiert werden). Eine einfache Möglichkeit scheint es zu sein, Farben als Eigenschaften anzusehen, die faktisch niemals instantiiert sind (wie es eine Variante des Projektivismus vorschlagen wird). Demnach gibt es weder in der Außenwelt, noch im Subjekt Zustände, die aktual die

4 Die Aktualismusthese (AT**) sagt, daß bei jeder $F$-Wahrnehmung auch immer eine instantiierte, $F$-phänomenale Eigenschaft vorliegen muß. Für den Subjektivisten wird es sich dabei um die Farbe F selbst handeln, weswegen er die hier dargelegten Schwierigkeiten erhält. Für den Objektivismus stellen sich diese Probleme jedoch nicht, da er - laut (AT*) - die $F$-phänomenale Eigenschaft bloß als das der (objektiven) Farbe $F$ entsprechende Quale deutet. Dieses ist natürlich immer genau dann instantiiert, wenn eine Farbwahrnehmung vom dazugehörigen Typ vorliegt; aber natürlich kann solch eine Wahrnehmung für den Objektivismus die Farbe $F$ immer noch fehlrepräsentieren. 
phänomenal präsentierten Eigenschaften besitzen können. Doch dann macht es gar keinen Sinn, von einer Repräsentation zu sprechen, weil zumindest in der aktualen Welt überhaupt keine nomologische Korrelation bestehen oder etabliert werden kann.

Somit können Farbwahrnehmungen nur dann die Eigenschaften $P$ repräsentieren, wenn ihr Auftreten manchmal von distinkten $P$-Tatsachen begleitet wird, und manchmal nicht. Dies ist die einzige Option, die übrigbleibt, da sowohl ausgeschlossen worden ist, daß immer $P$-Tatsachen vorliegen, als auch, daß faktisch niemals $P$-Tatsachen gegeben sind (vor dem allgemeinen Hintergrund, daß solche Tatsachen nicht ohne entsprechende Wahrnehmungen existieren können, da sie geistabhängig sind). Ist es nun möglich, daß Farbwahrnehmungen auftreten, ohne daß gleichzeitig die präsentierten Farbeigenschaften instantiiert sind? Da vorausgesetzt ist, daß die Farben $P$ nicht als Eigenschaften der Wahrnehmung selbst angesehen werden dürfen, will man eine Repräsentationsrelation behaupten, kommen als Farbträger nur von dieser distinkte Zustände des Subjektes in Frage, wobei sich drei Kandidaten anbieten: (i) mentale Zustände; (ii) cerebrale Zustände; (iii) oder Sinnesdaten. Die letzte Möglichkeit kann gleich ausgeschlossen werden, da der Indirekte Realismus bereits als widerlegt angesehen worden ist.

Die erste Alternative, die Farben als Eigenschaften mentaler Zustände postuliert, hat den schwerwiegenden Nachteil, daß sie auf ganz ähnliche Weise eine geist-interne Repräsentationsrelation als gegeben annehmen muß, die zudem noch genauso wie die normale Wahrnehmungsrelation beschaffen ist. Es wäre ganz natürlich, diese Repräsentation als eine Art von Introspektion aufzufassen. Doch Introspektion wird normalerweise so verstanden, daß es zu Überzeugungen höherer Ordnung führt, die insbesondere begriffliches Selbstwissen beinhalten: Wahrnehmungen können demnach nicht wirklich introspektierende Zustände sein. Zudem ist es üblich, die Wahrnehmungen an der „Schnittstelle“ von Gehirn und Geist zu lokalieren: alles, was sich epistemisch vor den Sinneserfahrungen befindet, ist somit nicht-mental. Und wäre der postulierte Träger der $P$-Eigenschaften wirklich mental, müßte er wohl auch direkt dem Bewußtsein mittels Aufmerksamkeit oder Introspektion zugänglich sein. Schließlich kann auch versucht werden, dafür zu argumentieren, daß eine solche intere wahrnehmungsähnliche Relation eine Sinnesdatentheorie automatisch mit sich 
bringt (vgl. Shoemaker (1994a)). Damit kann auch die erste Option zurückgewiesen werden.

Es bleibt somit nur noch die mittlere Alternative, die Träger der $P$-Eigenschaften cerebrale Zustände anzusehen. Die Frage, wie dann die Subjektivität der $P$-Eigenschaften garantiert werden kann, wenn sie von physikalisch vollständig beschreibbaren Gehirnzuständen instantiiert werden, ist sicherlich nicht so leicht zu beantworten; aber die Möglichkeit einer solchen, zufriedenstellenden Antwort soll hier nicht bezweifelt werden (die $P$ Eigenschaften können vielleicht als Relationen oder Dispositionen aufgefaßt werden). Da die Beziehung zwischen den fraglichen Gehirnzuständen und den Farbwahrnehmungen kausaler Natur sein werden (einschließlich mentaler Verursachung), ist es ohne weiteres vorstellbar, daß solche Sinneserfahrungen auftreten, ohne daß die in ihnen präsentierten $P$-Eigenschaften unbedingt immer instantiiert sein müssen. Doch der umgekehrte Fall ist natürlich durch die ontologische Geistabhängigkeit der $P$-Tatsachen ausgeschlossen: immer wenn eine bestimmte Farbtatsache vorliegt, gibt es auch die entsprechende Farbwahrnehmung.

Betrachten wir nun den konkreten Fall einer hinsichtlich der in ihr präsentierten $P$-Eigenschaft nicht-veridischen Wahrnehmung. Damit es sich um eine Illusion handeln kann, müssen die folgenden beiden Referenzbedingungen erfüllt sein: (i) der Gehirnzustand muß die Wahrnehmung kausal verursacht haben; (ii) der Gehirnzustand muß eine Eigenschaft $Q$ aufweisen, die von der Wahrnehmung präsentiert wird. Die kausale Verursachung kann vorausgesetzt werden, und ebenso der Umstand, daß der Gehirnzustand die Eigenschaft $Q$ tatsächlich instantiiert. Doch die Erfüllung der zweiten Bedingung ist trotzdem nicht möglich, weil keine von $P$ verschiedene Eigenschaft als angemessener Kandidat für $Q$ gefunden werden kann, die die $P$-Präsentation illusionär sein ließe. ${ }^{5}$ Dafür lassen sich zwei

5 Würde es nicht reichen, wenn wenigstens einfach eine (halluzinatorische) Fehlrepräsentation möglich wäre: dafür müßten keine Referenzbedingungen erfüllt werden? Eine solche nicht-referentielle (nicht „,vollständige“ - vgl. den Abschnitt über Referentialität) Repräsentationalität ist durchaus denkbar. Es ist nur fraglich, wie solche Fälle von Detektionen unterschieden werden können: wie also nichtdetektierende und fehlrepräsentierende Zuständen auseinandergehalten werden können, sobald eine Unterscheidung zwischen Illusion und Halluzination nicht mehr möglich ist. Zudem bleibt auch immer noch das Problem (b): für einen Farbgehalt Normalbedingungen zu bestimmen und eine evolutionär bestimmte 
Gründe nennen. Zuerst einmal erfordert (wahrscheinlich) jede sinnliche Repräsentation eine Lokalisierung im Raum. Dabei ist es an dieser Stelle gleich, ob sich dies nur auf den externen, objektiven Raum oder auch auf einen ,internen Raum“ innerhalb des Körpers beziehen kann, denn unsere Farbwahrnehmungen enthalten sicherlich nicht Informationen über die Position interner Gehirnzustände.

Doch selbst wenn diese These über die Gebundenheit der Repräsentationalität an Räumlichkeit nicht akzeptiert wird, bleibt noch ein zweites Problem bestehen: daß uns außer der Farbeigenschaften (und den die Außenwelt betreffenden, räumlichen Eigenschaften) keine anderen Eigenschaften mehr in Farbwahrnehmungen präsentiert sind. Soll der Gehirnzustand also als Referent der Präsentation aufgefaßt werden, muß die von ihm instantiierte Eigenschaft $Q$ selbst eine Farbe sein. ${ }^{6}$ Doch aufgrund der Subjektivität der Farben bedingt dies, daß es sich in Wirklichkeit nicht um eine $P$-, sondern um eine $Q$-Präsentation handelt. Es kann somit nicht der Fall sein, daß eine $P$-Präsentation vorliegt, die eine (Farb-)Illusion hinsichtlich der von dem Gehirnzustand instantiierten Eigenschaft $Q$ darstellt. Und damit kann auch die dritte Option keine Repräsentierbarkeit der Farbeigenschaften garantieren. Dieses Argument trifft im übrigen auch die beiden schon vorher zurückgewiesenen Alternativen. Damit kann der Subjektivismus die Repräsentierbarkeit von intern instantiierten, subjektiven Farben nicht aufrechterhalten. ${ }^{7}$

Funktion zu finden, damit diese Art von Gehalt nicht überflüssig wird.

6 Dieses Argument kann vielleicht noch dadurch verstärkt werden, daß eine $P$-Präsentation nur dann eine Illusion sein kann, wenn die tatsächlich instantiierte (und eigentlich präsentierte) Eigenschaft $Q$ ebenfalls eine Farbe ist (und zudem von $P$ verschieden). Bei Wahrnehmungen von komplexeren Eigenschaften ist dies sicherlich nicht der Fall: man kann ohne weiteres einen $L K W$ fälschlicherweise als eine Bretterbude oder eine Reklametafel sehen. Doch es ist nicht so klar, ob man zum Beispiel eine ganz bestimmte Eigenschaft eines Gegenstandes (wie hier etwa des Gehirnzustandes) inkorrekt als eine Farbe wahrnehmen kann, wenn es sich in Wirklichkeit gar nicht um eine Farbeigenschaft handelt. Somit erfordern sinnliche Farbillusionen vielleicht wirklich immer die Misrepräsentation einer instantiierten Farbe $Q$, die als (eine andere) Farbe $P$ gesehen wird.

7 Es wäre zudem nicht sehr leicht vorstellbar, wie die entsprechenden Normalbedingungen (oder die vielleicht dazugehörige, biologische Funktion) aussehen könnten. 
Ein noch offenstehender Ausweg ist es, subjektive Farben als Eigenschaften der externen Objekte zu postulieren, indem man ihnen einen relationalen oder dispositionalen Charakter zuspricht. Der Dispositionalismus (der Farben als über Farbwahrnehmungen definierte, dispositionale Eigenschaften der als farbig gesehenen Objekte in der Außenwelt ansieht) hat dabei gegenüber dem Relationalismus (der Farben als relationale Eigenschaften zwischen den wahrgenommenen Gegenständen und den diese wahrnehmenden Sinneserfahrungen postuliert) den Vorteil, daß er die Subjektivität soweit abschwächen kann, daß die Rigidizitätsintuition und die Objektivitätsthese unter Umständen modifziert auch vom Subjektivismus beibehalten werden können. Doch für die Frage nach der Repräsentationalität der Präsentationsrelation ist dies, wie gesagt, nebensächlich. Denn erneut ist allein die Frage entscheidend, ob Farbwahrnehmungen auftreten können, ohne daß die entsprechenden, präsentierten Farbeigenschaften wirklich von den Objekten instantiiert werden. Das Argument über die Referenzbedingungen funktioniert hier nicht, da ja visuelle Sinneserfahrungen auch räumliche Informationen über die Gegenstände liefern können, die kausal verantwortlich für das Auftreten der fraglichen Wahrnehmungen sind. Somit kann der Referent von Farbwahrnehmungen unabhängig von Farbeigenschaften oder -tatsachen bestimmt werden.

Doch nun entsteht ein neues Problem. Nehmen wir an, daß ein Gegenstand über die räumlichen Eigenschaften als Referent einer Rotwahrnehmung identifiziert worden ist. Ob in solch einem Fall eine veridische oder eine illusionäre Sinneserfahrung vorliegt, hängt üblicherweise davon ab, ob der Gegenstand tatsächlich Rot ist oder nicht. ${ }^{8}$ Nun sind Farbtatsachen laut Subjektivismus jedoch geistabhängig. Das heißt, die in Frage stehende Rottatsache kann nur dann existieren, wenn auch eine entsprechende Rot wahrnehmung gegeben ist (oder - im Falle des Dispositionalismus - wenigstens möglich wäre). In dem Beispiel ist diese Bedingung erfüllt. Will der Subjektivismus nun die Möglichkeit einer Illusion erlauben, muß er einen weiteren, von dem Auftreten der Rotwahrnehmung unabhängig existierenden Faktor benennen können, der ontologisch auf die Instantiierung der Roteigenschaft Einfluß nimmt. Liegt dieser Faktor in der beschriebe-

8 Die Frage, ob jeweils auch Illusionen hinsichtlich der ebenfalls repräsentierten Form- oder Ortseigenschaften vorliegen, ist hier und im weiteren Verlauf der Diskussion gänzlich irrelevant. 
nen Situation vor, dann bedingt er zusammen mit der aufgetretenen Rotwahrnehmung, daß die Rottatsache besteht. Fehlt der Faktor dagegen, dann liegt eine Rotillusion vor, weil eine Rotwahrnehmung allein noch nicht hinreichend (wohl aber notwendig) für die Existenz von Rottatsachen ist. Neben der üblichen ontologischen Abhängigkeit der Farbtatsachen von den Farbwahrnehmungen (马 Rot-Tatsache $\rightarrow$ 马 Rot-Wahrnehmung) muß also noch eine zweite, ontologische Abhängigkeit in umgekehrter Richtung postuliert werden (马 Rot-Wahrnehmung \& ヨ Faktor $\rightarrow$ G Rot-Tatsache), um Farbillusionen zu ermöglichen.

Worum kann es sich aber bei diesem Faktor handeln (der für sich allein genommen natürlich noch nicht eine Farbtatsache bedingen kann)? Es könnte sich dabei um einen farb-relativen Faktor handeln. Doch gäbe es für jede Farbeigenschaft unterschiedliche Faktoren, hätte dies zur Folge, daß es gar kein auch nur annähernd einheitliches Kriterium dafür gäbe, wann Farbwahrnehmungen im allgemeinen veridisch sind, und wann nicht. Doch dies widerspräche nicht nur unserem alltäglichen Umgang mit Farbwahrnehmungen und -urteilen, sondern es ist auch gar nicht abzusehen, welche Charakteristika als solche Faktoren in Frage kämen. Die einzig sinnvollen Kandidaten hierfür wären wahrscheinlich nur die Reflektanzeigenschaften der Objekte selbst. Doch wenn das Auftreten einer Rotwahrnehmung zusammen mit dem Vorhandensein des Reflektanzvermögens $S S R_{\text {ROT }}$ die Existenz einer Rottatsache implizieren würde, dann käme dies einem objektivistischen Informationalismus gleich. Und dieser sollte besser zu Gunsten eines normalen Objektivismus aufgegeben werden. Es ist folglich angebracht, auf die Einführung farb-relativer Faktoren zu verzichten.

Die Relationalisten und Dispositionalisten gehen üblicherweise auch von einem für alle Farbwahrnehmungen gemeinsamen Faktor aus: und zwar von Normalbedingungen. Doch wie kann der Subjektivismus diese bestimmen? Es ist natürlich möglich, die Normalbedingungen konventionell oder stipulativ zu bestimmen. Doch diese zugewiesene Repräsentationalität (assigned im Sinne Dretskes (1986): vgl. 133) entspricht natürlich nicht mehr unserer gewöhnlichen Vorstellung von der natürlich entstandenen Repräsentationalität mentaler Zustände - insbesondere, da Vergleichbares gerade nicht für den Fall der Wahrnehmungen von Formen gilt. Auch eine Übernahme der Normalbedingungen von der Repräsentation der Reflektanztypen kommt nicht in Frage. Diese Normalbedingungen ergeben 
sich automatisch aus Überlegungen darüber, wie wir die als Farben identifizierten Reflektanzeigenschaften angemessen und korrekt wahrnehmen können. Die evolutinär entwickelte Funktion des visuellen Wahrnehmungsapparates kann dabei nur unter ganz bestimmten Licht- und Kontextbedingungen erfüllt werden: wenn zum Beispiel mehrere Objekte gleichzeitig wahrgenommen werden, und wenn die Beleuchtung aus kontinuierlichen, in ihrer Intensitätsverteilung relativ gleichmäßigen Lichtwellen besteht. Dem Subjektivisten steht nun eine Übernahme dieser Funktionalität oder auch nur dieser Normalbedingungen nicht offen, da er Farben eben nicht als objektive Reflektanzen, sondern als subjektive Eigenschaften ansieht. Eine solche Übernahme käme somit ebenfalls einer Stipulation gleich. ${ }^{9}$

Die Dispositionalisten können nun noch versuchen, die für die Manifestierung der Farbdispositionen allgemein erforderlichen Bedingungen als „Normalbedingungen“ zu bestimmen. Diese setzen sich somit nur aus den auslösenden Umständen und den günstigen Hintergrundsbedingungen zusammen (der wesentliche Unterschied zu den Normalbedingungen des Objektivisten besteht dann in dem Umstand, daß die „Normalbedingungen“ der Subjektivisten keinen Hinweis mehr auf die besonderen Einschränkungen für die Licht- und Kontextbedingungen enthalten). Jede unter diesen „Normalbedingungen“ auftretende Farbwahrnehmung ist somit veridisch und impliziert die Existenz der entsprechenden Farbtatsache. Normalität beinhaltet dabei jedoch nur solche Bedingungen, die garantieren, daß das Auge des Betrachters vom Gegenstand ausgesandtes Licht empfängt, daß diese Reize im visuellen System in Farbinformation umgewandelt werden und daß schließlich eine Farbwahrnehmung hervorgerufen wird. Doch diese Bedingungen sind auch dann gegeben, wenn nur ein einzelnes Objekt betrachtet wird (void viewing conditions), oder wenn hochgradig chromatische Beleuchtung herrscht (Helson-JuddEffekt); und eventuelle Filter oder sonstige Beeinträchtigungen der Bahn des Lichtes können ebenfalls auftreten.

Es ist demnach zwar immer noch möglich, daß Farbwahrnehmungen

9 Dies zeigt sich auch in der Überlegung, daß es für einen Subjektivisten gar keinen Sinn macht, von einem Inversionsbeispiel hinsichtlich von Farben und Farbqualia zu sprechen. Vielmehr werden diese Fälle immer eine Inversion der Phänomenalität hinsichtlich der repräsentierten Reflektanzen betreffen. 
halluzinatorischen Charakter haben: wenn sie nämlich auf einem ganz anderen Wege verursacht werden. Doch sobald es zu einer Manifestierung einer Farbdisposition kommt, wird die Farbwahrnehmung veridisch sein müssen. Denn diese Manifestierung ist nur genau unter den „Normalbedingungen“ - das heißt: der Konjunktion von auslösenden Umständen und günstigen Hintergrundsbedingungen - möglich, da diese Manifestierungsbedingungen allain auf kausalen Gesetzmäßigkeiten beruhen. Hat eine visuelle Sinneserfahrung aufgrund der ebenfalls wahrgenommenen, räumlichen Eigenschaften einen Referenten, dann muß der Subjektivismus zugestehen, daß dieser Referent genau die Farbe hat, die er sinnlich zeigt: erscheint er uns rot, dann ist er auch rot. Diese Wahl der „Normalbedingungen" bringt also ebenfalls nicht die Möglichkeit von Farbillusionen mit sich. Es sind vielleicht noch andere Vorschläge denkbar, doch so wie es aussieht, kann auch der relationistische oder dispositionalistische Subjektivismus kein Kriterium benennen, mit dessen Hilfe das Auftreten einer veridischen von dem Auftreten einer illusionären Farbwahrnehmung unterschieden werden kann. ${ }^{10}$ Wie es sich bereits bei der Herleitung des Bikonditionals $(\mathrm{BK})$ aus der These $\left(\mathrm{IND}_{\mathrm{P}}\right)$ angedeutet hat, muß der Subjektivismus ohne Normalbedingungen auskommen. Damit ist aber insgesamt bereits gezeigt worden, daß der Farbsubjektivismus die Repräsentierbarkeit der Farben nicht aufrechterhalten kann.

Diese ganze Problematik zeigt sich in einem eindrucksvollen Beispiel, welches sich bei Tolliver findet (vgl. Tolliver (1994): 423f.). ${ }^{11}$ Der Edel-

10 Ohne solche Normalbedingungen ist jeder Gegenstand laut Subjektivismus auch genau dann rot, wenn er aktual als rot erscheint oder erscheinen könnte. Der subjektivistische Dispositionalismus und der Relationalismus könnten dieser Konsequenz vielleicht noch durch die Einführung - unabhängig von der Repräsentation der Reflektanztypen - evolutionär bestimmter Normalbedingungen für die Wahrnehmung von subjektiven Farben in Betracht ziehen. Doch auch diese hat zwei Mängel: zum einen werden sich die Normalbedingungen für den Farb- und den Reflektanzgehalt wohl decken, da aufgrund der These (ACT) Unterschiede im ersten auch immer Unterschiede im zweiten mit sich bringen (und umgekehrt); und zum anderen stellt sich dann immer noch das Problem (b): warum die Repräsentation von Farben unter anderem überhaupt evolutionär vorteilhaft sein sollte.

11 Hardin führt ebenso eine Reihe von Beispielen an (wie etwa die Benham-Scheibe - vgl. den Abschnitt gegen den Objektivismus ${ }_{\mathrm{ACT}}$ ), für die der subjektivistische Dispositionalismus keine Normalbedingungen (über die normale Ursache für die Manifestierung der fraglichen Farbdispositionen hinaus) bestimmen kann und so- 
stein Alexandrit hat aufgrund seiner kristallinen Beschaffenheit die Eigenschaft, im Sonnenlicht blaugrün auszusehen, während er bei Kerzenlich rot erscheint. Da in beiden Fällen normal verursachte Farbwahrnehmungen (im Sinne von normal verursachten Manifestierungen von Farbdispositionen) vorliegen, und da der Subjektivist nicht auf objektive Tatsachen über den Kristallaufbau des Juwels oder über die Unterschiede in den beiden Beleuchtungsarten zurückgreifen kann, um eventuelle Wahrnehmungsunterschiede zu erklären, muß er akzeptieren, daß der Edelstein sowohl blaugrün als auch rot ist (ein Objektivist kann dagegen zum Beispiel Kerzenlicht als nicht-normale Beleuchtung einstufen, weil es nicht die korrekte Detektion von Reflektanzeigenschaften erlaubt). Doch dies führt zu der Konsequenz, daß die betreffenden Farbwahrnehmungen nicht als falsch und folglich nicht auch als repräsentational angesehen werden können. Und zudem wird es - wie aber noch zu diskturieren ist - aller Wahrscheinlichkeit nach auch wenig Sinn machen, davon zu sprechen, daß in beiden Fällen die Farbigkeit des Edelsteines zutreffend detektiert worden ist, weil eine solche wechselhafte Detektion in unserem Alltag nicht bei der Individuation oder Wiedererkennung von Objekten eine Rolle spielen kann. Denn dafür ist das Phänomen der Farbkonstanz unabdinglich, welches der subjektivistische Dispositionalismus jedoch nicht erklären kann. ${ }^{12}$

Aber selbst wenn Farben wirklich von den Farbwahrnehmungen repräsentiert werden sollten, und es somit neben dem Reflektanzgehalt noch einen zusätzlichen Farbgehalt gibt, dann kommt immer noch das bereits oben erwähnte Argument (b) zum Tragen. Demnach liegt bei ein dem der kausalen Überdetermination ganz ähnliches Problem hinsichtlich der Erklärungskraft der repräsentierten Farben vor. Farbwahrnehmungen werden üblicherweise von Reflektanzprofilen SSR verursacht: ihr Auftreten ist infolgedessen kausal erklärbar. Die phänomenale Farbwahrnehmungstypen weisen zudem unter Normalbedingungen eine nomologische Korrelation mit den

mit zu unplausiblen Farbzuschreibungen kommt (vgl. Hardin (1988): 72f.).

12 Bei dem Edelstein Alexandrit handelt es sich natürlich um ein Extrembeispiel, welches auch Anhänger einer beliebigen anderen Theorie der Farben vor außerordentliche praktische Schwierigkeiten stellen wird. Der relationistische Subjektivismus kann jedoch zudem auch keine theoretische Klärung der Situation anbieten. 
(folglich repräsentierten) Reflektanztypen $S S R_{\mathrm{T}}$ auf: die entsprechenden, vorkommenden token sind somit auch repräsentational erklärt. Was bleibt also noch für die Farben zu erklären - insbesondere, da aufgrund der Aktualitätsthese (ACT) davon auszugehen ist, daß sie genauso feingradig wie die Reflektanztypen repräsentiert werden? Ohne jegliche Erklärungskraft scheint die Annahme der Repräsentiertheit der Farben jedoch vollkommen unbegründet zu sein (vgl. Jackson (1996): 202ff.). Auch läßt sich beispielsweise eine ähnliche Verdoppelung des Gehaltes bei Formwahrnehmungen nicht entdecken.

Zudem ist es mehr als fraglich, warum es für unser Überleben vorteilhaft sein sollte, wenn wir zusätzlich zu den Reflektanztypen auch noch subjektive Farben repräsentierten, da doch erstere bereits das Auftreten unserer Farbwahrnehmungen sowie unser farb-orientiertes Verhalten angemessen und vollständig erklären können. Und ganz davon abgesehen bleibt es offen, welche Beziehung dann überhaupt zwischen den beiden Arten von Gehalten bestehen sollte, wenn doch Unterschiede im Reflektanzgehalt nur mittels Unterschieden im Farbgehalt festgestellt werden können. Dies ist insbesondere deswegen von Interesse, da die Gültigkeit der Aktualitätsthese (ACT) es wohl mit sich bringen wird, daß Unterschiede im Reflektanzgehalt auch immer von Unterschieden im Farbgehalt begleitet würden (und umgekehrt): was wiederum darauf hinweisen würde, daß man vielleicht auch gut mit nur einem Gehalt auskommen könnte. Da es nicht abzusehen ist, wie diese ganzen Fragen zufriedenstellend zu beantworten sind, liegt es nahe, den sogenannten „Farbgehalt“" vielmehr als ein Farbquale aufzufassen, welches beispielsweise als eine Art von Gegebenheitsweise für die repräsentierte Reflektanz aufgefaßt werden kann.

Die Anfangshypothese hat sich auf jeden Fall bestätigt: eine Wahrnehmung kann keine Eigenschaft repräsentieren, die von ihr ontologisch abhängig ist. Zudem hat es sich herausgestellt, daß die ursprünglichen Implikationsverhältnisse zwischen den Merkmalen des repräsentationalen Aspektes wirklich bestehen. Insbesondere bedingt die Repräsentierbarkeit nicht nur eine (repräsentationale) Erklärungskraft, sondern auch die Objektivität (zumindest hinsichtlich der repräsentierenden Wahrnehmungen) der betreffenden Eigenschaften. Der Subjektivismus kann somit weder die These $\left(\mathrm{IND}_{\mathrm{R}}\right.$ ), noch die These (REP) vertreten (während der Objektivismus sehr 
wohl möglicherweise die These (PHE) behaupten kann). Zudem sind drei wichtige Resultate der bisherigen Überlegungen die folgenden Erkenntnisse. Erstens sind Farben nicht nur subjektiv, sondern zudem hat auch die Objektivitätsthese (OT) für sie (vielleicht mit Ausnahme der Farb dispositionen) keine Gültigkeit. Zweitens werden in Farbwahrnehmungen immer Farben phänomenal präsentiert. Und drittens können subjektive Farben nicht von den Wahrnehmungszuständen repräsentiert werden, von denen sie ontologisch abhängen.

$\mathrm{Da}$ die Repräsentationalität (oder auch eine andere, normative Beziehung) als Relation zwischen Farben und Farbwahrnehmungen ausgeschlossen werden kann, liegt es sehr nahe, die im zweiten Resultat erwähnte Präsentationsrelation so aufzufassen, daß sie der Aktualitätsthese ( $\left.A^{* *}\right)$ genügt. Dann besteht eine wechselseitige, ontologische Abhängigkeit zwischen Farbtatsachen und Farbwahrnehmungen (wobei noch offen ist, ob Farben von den Wahrnehmungen selbst instantiiert werden oder nicht): $W_{\mathrm{P}}$ $\leftrightarrow P(x)$. Der Relationalismus kann dieser Konsequenz wohl nicht ausweichen, will er eine nicht-dispositionalistische Theorie bleiben. Die wechselseitige Abhängigkeit kann nur dadurch umgangen werden, daß man entweder die Existenz von Farbtatsachen ganz leugnet, oder eben einen Dispositionalismus bevorzugt. Damit lassen sich nun die subjektivistischen Positionen genauer differenzieren. Es gibt vier mögliche Theorien (die erst in den folgenden Abschnitten im Detail erläutert werden sollen):

Den subjektivistischen Dispositionalismus, der Farben als externe, subjektive Dispositionen ansieht.

Den Relationalismus, der die wechselseitige, ontologische Abhängigkeit akzeptiert und Farben als (teilweise) externe Eigenschaften ansieht.

Den Wörtliche Projektivismus, der die wechselseitige, ontologische Abhängigkeit akzeptiert und Farben als interne Eigenschaften ansieht.

Den Bildliche Projektivismus, demzufolge es aktual gar keine Farbtatsachen gibt.

Die beiden ersten Theorien können dabei zu dem relationalistischen Subjektivismus zusammengefaßt werden, die beiden restlichen ganz allgemein 
zum Projektivismus. Wie sieht es nun mit der Möglichkeit aus, von einer Detektion der Farben zu sprechen? Die wechselseitige, ontologische Abhängigkeit ergibt zusammen mit der Detektion eine Präsentationsrelation, die der zwischen Wahrnehmungen und Sinnesdaten postulierten gleicht und aus denselben Gründen wie diese zurückgewiesen werden sollte (vgl. Hardins Gegenbeispiele in (1988): 96-109). Damit können weder der Relationalismus, noch der Wörtliche Projektivismus eine Detektionsrelation annehmen. ${ }^{13}$ Und für den Bildlichen Projektivismus kommt die Informationalität ebensowenig wie die oben bereits ausgeschlossene Repräsentationalität in Frage. Der subjektivistische Dispositionalismus kann als einziger die Detektion prinzipiell behaupten. Doch wie es sich herausstellen wird, stellt gerade er aus ontologischer Sicht die problematischste Position der vier Subjektivismen dar. Zudem wird die Annahme eines zweiten Gehaltes auch im Falle der Detektion eine Erklärungsüberdetermination mit sich bringen und sollte somit möglichst vermieden werden.

Auf eine wichtige Konsequenz, die sich für alle Farbsubjektivismen aus dem Umstand ergibt, daß subjektive Farben nicht repräsentiert werden können, sei noch kurz hingewiesen. Lassen sich keine veridischen von illusionären Farbwahrnehmungen unterscheiden, dann kann auch nicht das Phänomen der Farbkonstanz (oder -inkonstanz) darüber erklärt werden, daß Normalbedinungen hinsichtlich der Farben vorherrschen (oder nicht). $\mathrm{Zu}$ einer Erklärung muß der Subjektivist sich stattdessen auf die repräsentierten Reflektanzeigenschaften berufen. Eine weitere Folge ist, daß die Gegenstände in der Welt im Prinzip nahezu beliebige (und beliebig viele verschiedene) Farben aufweisen könnten, würden sich die Licht- und Kontextbedingungen dementsprechend ändern. Daß ein Buch uns üblicherweise als rot erscheint, schließt nicht aus, daß wir es unter ganz anderen, geeignet gewählten Beleuchtungsbedingungen als braun, violet oder hellgelb sehen. Noch stärker wird dieser Effekt bei typischerweise achromatisch aussehenden Objekten vorkommen. Der Subjektivismus ist in solchen Fällen gezwungen, zu sagen, daß der betreffende Gegenstand wirklich diese untypische Farbe „hat": oder jedenfalls hat er keine Möglichkeiten - außer bloße Stipulation -, dies zu leugen Für den Projektivisten, der eine ,interne Farbigkeit" auf die Welt gelegt sehen will, ist dies kein Problem. Es wird

13 Für die Variante des Wörtlichen Projektivismus, die Farben mit Farbqualia identifiziert, stellt sich diese Frage natürlich von vorneherein nicht. 
sich jedoch als eines für die relationistischen Theorien herausstellen, da die von der (partiellen) Externalität der Farbtatsachen ausgehen möchten.

\subsection{Der relationalistische Subjektivismus}

Der relationalistische Subjektivismus definiert Farben über phänomenal individuierte Farbwahrnehmungen. Er kann grundsätzlich in zwei Varianten auftreten: entweder werden Farben als genuine Relationen angesehen, die zwischen den als farbig gesehenen Objekten und den entsprechenden Farb wahrnehmungen des Subjektes bestehen; oder Farben werden als Dispositionen zur Verursachung von solchen Sinneserfahrungen analysiert, wobei diese dispositionalen Eigenschaften allein von den wahrgenommenen Objekten instantiiert werden. In beiden Fällen ist es von besonderer Bedeutung, daß Farben wenigstens teilweise eine externe Instantiierheit zuerkannt wird. Die folgende Diskussion wird sich nun im wesentlichen auf den Dispositionalismus konzentrieren. Nur an ganz bestimmten Stellen, wenn es für die Diskussion nützlich oder erforderlich ist, werde ich auf Abweichungen hinweisen, die für den genuinen Relationalismus gelten.

Diese Beschränkung hat drei Gründe. Erstens teilen beide Positionen sehr ähnliche Schwierigkeiten miteinander. Zweitens hat der Dispositionalismus vielleicht den Vorteil, Farben nicht als so strikt geistabhängig anzusehen wie noch der genuine Relationalismus. Denn die dispositionalistische Analyse erlaubt, daß die Objekte in der Außenwelt auch dann ihre Farbigkeit behalten, wenn sie nicht faktisch von einem Subjekt betrachtet werden; und wahrscheinlich sogar selbst dann, wenn es zwar aktual gar keine farbwahrnehmenden Subjekte gibt, aber die Möglichkeit besteht, daß es welche (ohne weiteres) geben könnte. In diesem, letzteren Sinne wären Gegenstände in der aktualen Welt auch dann noch farbig, wenn alle Menschen und Tiere aussterben würden, da die Instantiierung von Farbdispositionen deren Manifestierung nicht bedingt, sondern nur deren Manifestierbarkeit (die gegeben ist, da zum Beispiel wieder Leben auf der Erde entstehen könnte). Für den genuinen Relationalismus existieren dagegen Farbtatsachen immer nur solange, wie sie wahrgenommen werden, da Relationen immer die Existenz beider Relata voraussetzen. Und schließlich ist es, drittens, meines Wissens der Fall, daß der genuine Relationalismus als Theorie 
der Farben von niemandem vertreten wird. ${ }^{14}$

\subsubsection{Der subjektivistische Dispositionalismus}

Die subjektivistische Variante des Dispositionalismus genießt nicht nur deswegen eine außerordentliche Popularität (wie sonst fast keine andere Theorie der Farben), weil sie in der empiristischen Tradition der Neuzeit eine herausragende Stellung eingenommen hat, sondern auch, weil sie dem Anspruch gerecht zu werden scheint, die repräsentationale Seite der Intuitiven Farbkonzeption - von der Objektivität natürlich einmal abgesehen mit der phänomenalen zu versöhnen. Aus den Ergebnissen der Wissenschaft der Farben zieht der subjektivistische Dispositionalismus den Schluß, daß ein reiner Objektivismus nicht aufrechterhalten werden kann; und dem Projektivismus gegenüber möchte er den Vorteil behaupten, wenigstens einige repräsentationale Merkmale für die Farbeigenschaften beibehalten zu können, insbesondere die Repräsentiertheit und die Externalität. Nimmt man diesen Anspruch ernst, so wird sich diese Form des Dispositionalismus nicht eindeutig dem Subjektivismus zurechnen lassen; und er wird tatsächlich auch manchmal als eine Position zwischen Subjektivismus und Objektivismus angesehen (vgl. Johnston (1992)). Im allgemeinen folgen die Dispositionalisten dem bereits eingeführten Schema $\left(D_{M}\right)$, so daß sich die Position wie folgt charakterisieren läßt, geht man von der als epistemische Notwendigkeit formulierten Analysethese (ANA) aus (das heißt: $\left.F_{\mathrm{i}}:=P_{\mathrm{i}}\right)^{: 15}$

14 Averill nennt seine neuere Theorie zwar eine ,relationale“, aber sie ist tatsächlich eine dispositionale (vgl. Averill (1992); sowie die Einleitung zu Byrne \& Hilbert (1997a): xii). Ähnliches läßt sich über die Theorie der Farben von McDowell (1985) sagen. Interessanterweise postuliert Shoemaker neuerdings solche subjektiven, relationalen und phänomenalen Eigenschaften, die er zwar nicht „Farben“ nennt, deren Annahme aber mit denselben Schwierigkeiten verbunden ist wie die Annahme eines subjektivistischen Relationalismus (doch dazu mehr erst im Schlußkapitel; vgl. zudem Shoemaker ((1994b); (1995)).

15 Vgl. zur Charakterisierung der dispositionalistischen Position die Einleitung in Byrne \& Hilbert ((1997a): xx-xxi). - Vertreter eines solchen Dispositionalismus sind: Averill (1992); Johnston (1992); Peacocke (1984); Evans (1980); McGinn (1983); O'Shaughnessy (1986); McDowell (1985); und voraussichtlich auch 
(DIS) $\quad P_{\mathrm{i}}:=$ die Disposition, unter Normalbedingungen in einem Subjekt

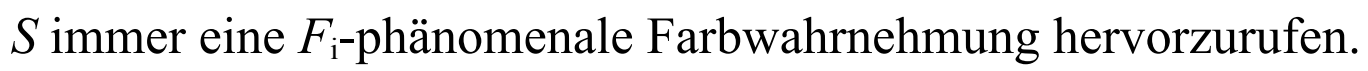

Solche Dispositionen können auch Reaktionsdispositionen (response dispositions) genannt werden, da sie über einen in Subjekten hervorgerufenen, mentalen Zustand als Wirkung definiert werden (vgl. Johnston (1992): 147). Diese Analysethese (DIS) drückt nun eine begriffliche Wahrheit aus und gilt somit in allen möglichen Welten mit farbwahrnehmenden Subjekten für die betreffenden Normalbedingungen. Die ontologische Subjektoder Geistabhängigkeit zeigt sich in dem (sehr wahrscheinlichen) Umstand, daß Subjekte aus verschiedenen Spezies dieselben Gegenstände als Träger unterschiedlichster Farben sehen können (vgl. McGinn (1983): 9f.). Ein Objekt kann somit beliebig viele Farben gleichzeitig instantiieren (wie es interessanterweise auch bereits eine Konsequenz des objektivistischen Dispositionalismus gewesen ist). Aufgrund des, biologisch betrachtet, gleichen Aufbaues der Gehirne kann hinsichtlich einer bestimmten Spezies von einer Intersubjektivität unter den Farbwahrnehmungen der einzelnen Individuen ausgegangen werden.

Für den Relationalismus muß selbstverständlich eine andere Analysethese als für den Dispositionalismus formuliert werden. Eine relationale Farbeigenschaft kann sinnvollerweise nur dann vom Gegenstand instantiiert werden, wenn zum einen eine Farbwahrnehmung mit einem bestimmten Farbqualia vorliegt und zum anderen diese den betreffenden Gegenstand als (über andere, repräsentierte Eigenschaften und eine Kausalrelation identifizierte) Referenten hat. Damit superveniert die entsprechende Farbtatsache jedoch auf zwei verschiedenen Tatsachen: einerseits auf der Instantiierung eines Farbquale, welches überhaupt erst angibt, um welche Farbe es sich bei der Relation handelt; und andererseits auf der Instantiierung derjenigen physikalischen Eigenschaften des Gegenstandes, die dafür verantwortlich sind, die Referenzbedingungen zu erfüllen. Letztere werden wohl die Reflektanzeigenschaften sein (und eventuell auch noch räumliche Eigenschaften). Es ergibt sich also:

Wiggins (1987). 
(REL) $\quad P_{\mathrm{i}}:=$ die Relation, die auf den relevanten Reflektanzeigenschaften und dem $F_{\mathrm{i}}$-Quale einer Farbwahrnehmung im Subjekt $S$ supervenieren.

Es ist, wie bereits gesagt, ein erklärtes Ziel der meisten Dispositionalisten, sowohl der Repräsentationalität als auch der Phänomenalität der Farben gerecht werden zu können. Daß ein Dispositionalismus tatsächlich nur Merkmale entweder des einen oder des anderen Aspektes der Intuitiven Farbkonzeption einfangen kann, haben für die objektivistische Variante die Überlegungen zur Plausibilität des Repräsentationalismus und für die subjektivistische Variante die obige Argumentation gezeigt. Während der objektivistische Dispositionalismus somit aller Voraussicht nach auf die Phänomenalität verzichten muß, kann der subjektivistische Dispositionalismus die Farbdispositionen nicht mehr als repräsentierte Eigenschaften ansehen (und sinnvollerweise ebensowenig als detektierte). Für letzteren bleibt damit doch kein vermeintlich objektivistischer Charakterzug bestehen: es handelt es sich um einen reinen Farbsubjektivismus. Die (relativ schwache) Subjektivität der Farbdispositionen läßt sich dabei auf den Umstand zurückführen, daß ihre Instantiierungen auf dem Bestehen bestimmter Naturgesetzmäßigkeiten supervenieren, die wesentlich einen mentalen Wahrnehmungstypus beinhalten. Die hier vorgestellten Positionen erwarten nun einige, schwerwiegende Probleme, die, wie es scheint, unausweichlich dazu führen werden, daß der subjektivistische Dispositionalismus, und auch der Relationalismus, als plausible Theorien der Farben nicht mehr in Frage kommen.

\subsubsection{Unplausibilität des subjektivistischen Dispositionalismus}

Zuerst einmal steht der Dispositionalismus einem ganz besonderen Problem gegenüber: den Begriff einer subjektiven Reaktionsdisposition ontologisch angemessen zu interpretieren. Bringt man den subjektivistischen Dispositionalismus mit einer allgemeinen Ontologie der Dispositionen zusammen, wird sich bereits eine erste Unplausibilität offenbaren. Für den Relationalismus ergibt sich eine vergleichbare Schwierigkeit nicht, da Relationen in einem kategorialen Weltbild ohne weiteres Platz finden. Ein 
Hinweis darauf, daß indessen der dispositionale Charakter recht problematisch werden könnte, findet sich (ohne daß er weiter ausgeführt wird) bereits bei Wright formuliert, der sich dabei auf die dispositionalistische Theorie von Johnston bezieht.

„These are agreeable reflections and surely do respond to elements in our intuitive thinking about dispositions. The question is whether to expect that they can be developed with enough precision to give effective guidance in the drawing of the Euhthyphro contrast, conceived as proposed. No less is demanded than a general account of what a dispositional characteristic is; and the account must be formulated in such a way that means are provided to adjudicate controversial cases - properties which, like colour or ethical value, do not wear their response-dispositionality on their sleeves.“ (Wright (1992): 138)

In den allermeisten Fällen gehen die Vertreter eines solchen Dispositionalismus von zwei Umständen als gegeben aus: zum einen wird die Möglichkeit einer ontologischen Theorie von Dispositionen im allgemeinen und von Reaktionsdispositionen (response dispositions) im besonderen vorausgesetzt; und zum anderen wird es als selbstverständlich angenommen, daß solche Dispositionen, die über Farbwahrnehmungen als in Subjekten hervorgerufene Reaktionen definiert werden, beim Auftreten der betreffenden Sinneserfahrungen auch repräsentiert werden. Wie es sich herausgestellt hat, kann die Annahme der Repräsentiertheit der Farben nicht beibehalten werden. Im folgenden soll nun argumentiert werden, daß subjektive Dispositionen in dieser Art ontologisch nicht wirklich angenommen werden sollten, so daß der ganze subjektivistische Dispositionalismus, seiner Basis beraubt, unplausibel und für eine Analyse der Natur der Farben nicht mehr in Frage kommen wird.

Eine ontologische Betrachtung der Dispositionen hat gezeigt, daß es im Grunde nur zwei sinnvolle Weisen gibt, dispositionale Zuschreibungen zu interpretieren: entweder faßt man sie eng-dispositional auf und nimmt die jeweiligen, kategorialen Basiseigenschaften als Wahrmacher; oder man versucht, einen Rest der Dispositionalität beizubehalten, indem man die zugeschriebenen Dispositionen (im weiten Sinne) mit deren disjunktiven Basismengen gleichsetzt. Ganz gleich, für welche Lesart man sich hinsichtlich der Farbdispositionen entscheidet, in beiden Fällen werden sie letztlich als objektive Eigenschaften aufgefaßt werden müssen. Denn so- 
wohl die jeweiligen, kategorialen Basen (die einzelnen Reflektanzprofile) als auch die Disjunktionen (die Reflektanztypen), die sich ja aus den Basen als Disjunkten zusammensetzen, sind physikalisch beschreibbare Eigenschaften. Dahinter verbirgt sich der Umstand, daß die drei oben eingeführten Bestimmungen von Farben als Dispositionen $\left(D_{L}\right),\left(D_{v S}\right)$ und $\left(D_{M}\right)$ ineinsfallen, wenn Dispositionen auf die disjunktiven Basismengen reduziert werden. Die subjektiven Farbdispositionen werden somit auf einmal zu objektiven Disjunktionen.

Der Subjektivist kann natürlich versuchen, eine Alternative Analyse der Dispositionalität von Eigenschaften zu liefern. Es ist insbesondere möglich, Dispositionen als genuine Universalien - neben den kategorialen Eigenschaften - zuzulassen. Doch dies bringt reichlich Schwierigkeiten allgemeiner, ontologischer Art mit sich (vgl. Armstrong (1997): 83f.; 248ff.). Zuerst einmal bedingt dies hinsichtlich von Dispositionen die Aufgabe der Gültigkeit des ontological free lunch; doch damit wird es gleichzeitig sehr unwahrscheinlich, daß diese These trotzdem noch für andere Eigenschaftsarten (wie Disjunktionen oder Negationen) oder Entitäten (wie aus inhomogenen Teilen stipulierte Ganze) gelten sollte. Daneben erzwingt die Annahme von dispositionalen Universalien die fragwürdige, paralle Existenz von kausalen, kontingenten Naturgesetzmäßigkeiten einerseits und dispositionalen, notwendigen andererseits $(83 ; 250 \mathrm{ff}$.). Schließlich bleibt das ontologische Verhältnis der beiden Eigenschaftsarten untereinander und die Natur ihrer Wechselwirkungen (wie Realisierung und Manifestierung) unbestimmt (vgl. Armstrong (1997): 75ff.; 83f.; 248ff.). Aufgrund dieser Schwierigkeiten scheint die Annahme von dispositionalen Universalien vor dem Hintergrund eines Kategorialismus mehr als unplausibel zu sein. ${ }^{16}$ Und da der subjektivistische Dispositionalismus aber wesentlich von einem solchen Ausweg abhängt, muß er diese Unplausibilität direkt übernehmen. Für den Relationalismus ergibt sich dagegen, wie gesagt, diese Schwierig-

16 Eine Aufgabe des Kategorialismus kommt ebenfalls nicht in Frage, da wenigstens kausale und raum-zeitliche Eigenschaften, und wahrscheinlich auch die vorkommenden Manifestationen der einzelnen Dispositionen, als kategorial angenommen werden müssen (vgl. Armstrong (1997): 72, 80; sowie Einleitung zu Crane (1997): 5). Und Mischtheorien, die von einer Art von Universalien ausgehen, denen sie sowohl einen kategorialen als auch einen dispositionalen Charakter zuschreiben, sind ebenfalls wohl gegenüber einem Kategorialismus erheblich im Nachteil (vgl. Armstrong (83f.; 250ff.). 
keit erst gar nicht, da Relationen aus ontologischer Sicht im Vergleich zu Dispositionen ganz unproblematisch sind.

Ein weiteres Hindernis stellt - diesmal für beide Positionen gleichermaßen - in gewissem Sinne die geforderte (partielle) Externalität der Farbeigenschaften dar. Denn die einzige Motivation für einen Subjektivisten, dieses Merkmal den Farben zusprechen zu wollen, kann der Umstand sein, daß Farbwahrnehmungen einen Farbgehalt haben, das heißt, neben den Reflektanzen auch Farben repräsentieren oder detektieren. Gibt es einen derartigen Gehalt nicht, dann sind Farben allein phänomenal präsentierte Eigenschaften und unterscheiden sich als solche in nichts von Farbqualia. Insbesondere läßt es sich sogar argumentieren, daß die Farbwahrnehmungen über einen Farbgehalt verfügen müssen, wenn die Farben (zum Teil) von den externen Objekten instantiiert werden. Nehmen wir an, daß eine Rotwahrnehmung vorliegt, die einen Gegenstand als (über die räumlichen Eigenschaften bestimmten) Referenten hat, der tatsächlich die dispositionale (oder relationale) Farbe Rot instantiiert. Wenn nun also die Rotwahrnehmung die Farbe Rot präsentiert (und wir diese zudem sogar als Eigenschaft des Gegenstandes sehen) und ihr Referent die Farbe Rot instantiiert, dann ist die beste Interpretation hierfür, daß eine Repräsentations- oder Detektionsrelation zwischen der Farbeigenschaft und der Farbwahrnehmung besteht.

Aber so einfach ist es natürlich nicht. Da sich die Repräsentiertheit subjektiver Farben bereits als unhaltbar erwiesen hat, können wir uns auf die Detektiertheit konzentrieren. Diese liegt nur dann vor, wenn eine nomologische Korrelation zwischen Eigenschaft und Sinneserfahrungstyp vorliegt. Doch gerade dies ist hier der Fall. Der kausal für die Farbwahrnehmung verantwortliche Referent zeigt ja immer genau die subjektive Farbe, die in der Farbwahrnehmung präsentiert ist. Denn nach den relationalistischen Theorien bestimmen die phänomenalen Sinneserfahrungen, welche Farbtatsache (wenn überhaupt) vorliegt. Ist, wie im Beispiel, der Fall einer Halluzination ausgeschlossen, dann ist der Gegenstand demnach wirklich rot, wenn die Wahrnehmung die Eigenschaft Rot präsentiert, und grün, wenn die Eigenschaft Grün präsentiert wird. Für die relationalistische Variante sollte dies klar sein, da diese Relationen ja unter anderem auf der Instantiierung der jeweiligen Farbqualia superveniert. Doch auch für den Dispositionalismus ergibt sich diese Konsequenz. Besitzt der Gegenstand eine sub- 
jektive Farbdisposition, dann sind die Umstände entweder so beschaffen, daß dessen Basis das Auftreten einer Farbwahrnehmung verursacht, oder so, daß die Manifestierung eben nicht erfolgt. Und im Falle einer Manifestierung der Disposition bestimmt natürlich immer allein die Farbwahrnehmung, welche Farbdisposition der Gegenstand besitzt: ist es zum Beispiel eine Rotwahrnehmung, hat der Gegenstand die Farbdisposition Rot.

Nach beiden relationistischen Subjektivismen sind Farbwahrnehmungen entweder ganz allgemein Halluzination, oder aber sie zeigen eine nomologische Korrelation zu den in den Gegenständen (partiell) instantiierten Farbeigenschaften. Und genau dies erfüllt die Bedingung für das Bestehen einer Detektionsrelation. Demnach muß ein Subjektivismus, der Farben (auch) als Eigenschaften der externen, wahrgenommenen Gegenstände ansehen möchte, von einem informationalen Gehalt ausgehen: subjekte Farb dispositionen (oder -relationen) werden detektiert. Da der Relationalismus, wie oben gezeigt, von einer wechselseitigen, ontologischen Abhängigkeit zwischen Farbtatsachen und Farbwahrnehmungen ausgehen muß, gerät er damit in eine gefährliche Nähe zu einer Sinnesdatentheorie, die eine vergleichbare Präsentationsrelation zwischen den Sinnesdaten und den Wahrnehmungen postuliert. Doch ganz davon abgesehen sehen sich beide relationalistischen Positionen den oben schon genannten Schwierigkeiten ausgesetzt: auf der einen Seite ist die Beziehung des informationalen Farbgehaltes zum repräsentationalen Reflektanzgehalt ungeklärt, und zum anderen besteht das Problem der Erklärungsüberdetermination.

Letztere drückt sich nun darin aus, daß zwei verschiedene Eigenschaften - die Farbe und das Reflektanzprofil - explanatorisch hinreichend sind für das Auftreten eines token des betreffenden Farbwahrnehmungstypes. Dieser Umstand weist bereits daraufhin, daß es eigentlich überflüssig zu sein scheint, die Farbeigenschaft dem Gegenstand zuzuschreiben zu wollen (daß er zumindest das Reflektanzvermögen besitzt, kann ja wohl vorausgesetzt werden). Daß diese Annahme überdies unplausibel ist, zeigt die folgende Überlegung. Unter bestimmten, wechselnden Beleuchtungs- und Kontextbedingungen wird ein- und derselbe Gegenstand jeweils ganz andere Farben zeigen. $\mathrm{Zu}$ jeder beliebigen Farbe wird sich dabei wahrscheinlich eine Wahrnehmungssituation herstellen lassen, in der das Betrachten des Objektes zu genau solchen Farbwahrnehmungen führen wird, in denen die gewünschte Farbe präsentiert wird (indem zum Beispiel bestimmtes, 
monochromatisches Licht verwendet wird). Der Subjektivismus kann nun nicht sagen, daß die einen Farbwahrnehmungen korrekt und die anderen inkorrekt sind, da ihm hierfür ein nicht-stipulatives Kriterium fehlt: weswegen es sich ja gerade nur um Detektionen, und keine Repräsentationen, handeln kann. Daraus muß aber geschlossen werden, daß alle diese Farbwahrnehmungen (sofern sie nicht generell Halluzinationen sind) einen veridischen informationalen Gehalt aufweisen.

Für den Dispositionalismus ergibt sich damit die unausweichliche Konsequenz, daß jeder einzelne Gegenstand alle Farbeigenschaften gleichzeitig instantiiert (will er nicht Farbtatsachen von den vorherrschenden Beleuchtungsbedingungen abhängig machen). Denn für alle Farben lassen sich günstige Licht- und Kontextbedingungen finden, so daß sie entsprechend in visuellen Sinneserfahrungen von dem betreffenden Objekt präsentiert werden. Der objektivistische Dispositionalismus entgeht dieser Folge, weil er auf substantielle Normalbedingungen zurückgreifen kann. Für ihn können Gegenstände nur für unterschiedliche Spezies auch verschiedene Farben haben. Der subjektivistischen Variante steht dieser Weg über Normalbedingungen jedoch nicht offen. Alle farbigen Gegenstände instantiieren für jedes einzelne Subjekt aus einer Spezies alle möglichen Farben gleichzeitig: doch dann sind alle diese Gegenstände für das betreffende Subjekt gleichfarbig. Der subjektivistische Dispositionalismus kann damit nicht erklären, wie wir Objekte aufgrund ihrer Farbigkeit diskriminieren, individuieren oder auch wiedererkennen können. Die Farben spielen aus ontologischer Sicht absolut keine Rolle in unserem Verhalten zur Welt (höchstens noch die Farberscheinungen relativ zu den Wahrnehmungsbedingungen).

Der Relationalismus zeigt zwar im Grunde eine sehr ähnliche, aber doch längst nicht so starke Konsequenz: ihm zufolge instantiiert ein Gegenstand nicht alle Farben gleichzeitig, sondern höchstens hintereinander (und da auch nur so viele verschiedene, wie er unter verschiedenen Wahrnehmungsbedingungen betrachtet wird). Somit wird er unser auf die Farbigkeit der Gegenstände ausgerichtetes Verhalten aller Wahrscheinlichkeit immer erklären können, da üblicherweise jeweils ontologische Farbunterschiede faktisch bestehen werden (dies wird so auch für die Projektivisten gelten). Aber der entscheidende Punkt ist hier auch gar nicht, daß unser Verhalten eventuell nicht erklärt werden kann. Denn selbst dem Dispositionalisten ist die Möglichkeit gegeben, dies durch Bezug auf die 
Reflektanzeigenschaften zu leisten. Daß alle Gegenstände in gewissem Sinne gleichfarbig sind, ist schon problematischer (allerdings nicht aus ontologischer Sicht) und widerspricht vehement unseren Intuitionen; aber auch dieser Umstand kann eventuell akzeptiert werden, da immerhin ein Gegenstand relativ zu den äußeren Bedingungen nur jeweils in einer Farbe präsentiert wird.

Was in Frage stehen sollte - und zwar gerade hinsichtlich des Dispositionalismus -, ist vielmehr die Behauptung, daß Farben wirklich noch genuine Eigenschaften der Gegenstände sein können. Es macht wohl nicht mehr viel Sinn, innerhalb einer derartigen Theorie der Farben Äußerungen wie die folgende zu treffen: ,der Gegenstand vor mir erscheint zwar nur als rot, aber er instantiiert in Wirklichkeit die Eigenschaften Rot, Kobaltblau, die Farbe meines Hemdes sowie alle anderen Farben ebenfalls“ (ob nun gleichzeitig oder möglicherweise nacheinander). Unter solchen Umständen verlieren Farbzuschreibungen all ihren Wert - wie sie, ontologisch betrachtet, ebenfalls ihre Erklärungskraft hinsichtlich des Auftretens von Farb wahrnehmung und voraussichtlich auch hinsichtlich unseres auf Farbphänomene abzielenden Verhaltens einbüssen. Was kann es schon noch bedeuten, eine Farbe zu besitzen, wenn ein beliebiger Gegenstand in der Außenwelt alle existierenden Farben gleichzeitig instantiiert, oder sie jederzeit in der aktualen Welt nacheinander instantiieren kann, ohne daß sich seine intrinsische Beschaffenheit oder die betreffenden Subjekte oder die herrschenden Naturgesetzmäßigkeiten ändern müßten? Im Grunde kann es gar nichts mehr bedeuten. Es ist bei weitem plausibler, die Idee der Externalität und der Detektiertheit der subjektiven Farben aufzugeben und einen Projektivismus anzunehmen.

Und es gibt möglicherweise noch einen weiteren Einwand gegen die beiden relationalistischen Positionen, der ebenfalls wiederum hauptsächlich gegen den Dispositionalismus gerichtet ist. Die Grundannahme des Subjektivismus besteht in den Thesen $\left(\mathrm{IND}_{\mathrm{P}}\right)$ und $(\mathrm{PHE})$ : daß Farben phänomenale Eigenschaften sind. Offensichtlich sind jedoch zuerst nur die Farbqualia phänomenal. Werden Farben also nicht mit diesen identifiziert, dann müssen sie die Phänomenalität von diesen auf die eine oder andere Weise übertragen bekommen (es ist zu beachten, daß beide relationalistischen Subjektivismen davon ausgehen, daß Farben über Farbwahrnehmungen definiert sind, und nicht umgekehrt). Der Relationa- 
lismus kann diese Übertragung vielleicht noch recht einfach erklären, da die Farbrelationen ja unter anderem auf dem phänomenalen Charakter der betreffenden Wahrnehmunh supervenieren. Doch für den Dispositionalismus ist dies weitaus weniger einsichtig, weil vor allem Gegenstände auch dann ihre phänomenalen Farben instantiieren können sollen, wenn keine entsprechenden Farbwahrnehmungen auftreten oder sogar gerade auch keine farbwahrnehmdenen Subjekte existieren (und die Überlegungen zum Objektivismus ${ }_{\mathrm{NEC}}$ haben gezeigt, daß die Phänomenalität für dispositionale Eigenschaften nicht so einfach beizubehalten ist). Es ist demnach nicht einmal klar, ob der Relationalismus und, vor allem, der Dispositionalismus die Grundvoraussetzung für einen Subjektivismus erfüllen. Alles in allem tut ein Vertreter von einer dieser beiden Positionen gut daran, entweder einen objektivistischen Dispositionalismus oder einen Projektivismus anzunehmen. Der subjektivistische Relationalismus ist keine angemessene Alternative.

„Some philosophers suggest that colour is a relation holding between our minds and external objects, but this is mysterious in the extreme." (Armstrong (1997): 59)

Tatsächlich läßt sich nun innerhalb der Literatur auch eine entsprechende Zweiteilung der Tendenzen und Neigungen nachweisen. Auf der einen Seite zeigt die Theorie Johnstons, wie oben bereits angedeutet, von vornehe rein schon eine eindeutige Nähe zu einem Farbobjektivismus. Zwar lehnt er Farben als Disjunktionen ab, aber die dafür entscheidenden Argumente gegen die Sichtbarkeit und die Rechtfertigungskraft von primären Qualitäten sind bereits zurückgewiesen worden (vgl. Johnston (1992): 149ff.; sowie den Abschnitt gegen den Objektivismus ${ }_{\mathrm{ACT}}$ ). Doch es gibt noch einen weiteren Hinweis darauf, daß Johnstons Position nicht allzuweit von einem Objektivismus entfernt ist: sie läßt sich nicht nur mit der Rigiditätsintuition in Einklang bringen, sondern Johnston zieht diese Möglichkeit auch ernsthaft in Erwägung (vgl. Johnston (1992): 155, 159). Auf der anderen Seite sind die Theorien von Peacocke und McGinn wohl eher als projektivistische Positionen anzusehen. Da Peacocke phänomenale Eigenschaften des Gesichtsfeldes (sensational properties) als introspektiv zugänglich annimmt, bietet es sich an, ihn in die Nähe des entsprechenden Projektivis- 
mus zu rücken: insbesondere, da eine Akzeptanz dieser Eigenschaften wahrscheinlich unvermeidlich zu der Ansicht führen wird, daß deren farbphänomenale Charakteristika auf die repräsentierten Objekte in der Welt projeziert werden (vgl. Byrne \& Hilbert (1997c): Fn. 16). ${ }^{17}$ Und eine genauere Lektüre des Buches von McGinn wird offenbar werden lassen, daß dieser ebenfalls keine genuine Repräsentiertheit der Farben annimmt, da für ihn Farbtatsachen und phänomenale Farbwahrnehmungen nicht auseinandergehen können (im Sinne vom Prinzip des esse est percipi - vgl. auch McGinn (1983): 8; 11).

„Being red consists in looking red.“ (McGinn (1983): 6)

Daß ein Dispositionalist eine dieser beiden Alternativen wählen sollte, ergibt sich auch aus den zu Anfang des Subjektivismuskapitel über die Kategorisierung der subjektivistischen Positionen angestellten Überlegungen. Dort ist gesagt worden, daß ein nicht-physikalistischer Dispositionalismus Farben über die mit ihnen verbundenen Farbwahrnehmungen definiert. Um eine Zirkularität der Analyse zu vermeiden, können die phänomenalen Farbwahrnehmungstypen somit nicht wiederum über die Farbeigenschaften selbst individuiert werden. Vielmehr sind hierfür die - von den Farben zu unterscheidenden - Farbqualia erforderlich, welche von den Farbwahrnehmungen instantiiert werden. Aber nun stellt sich die Frage, was Farben dann überhaupt für Eigenschaften sein können. Der einfachste Vorschlag ist es sicherlich, Farben als die repräsentierten (oder detektierten) Eigenschaften anzusehen. Doch dies hat nicht nur die Konsequenz, daß Qualia wegen der Zirkularitätsdrohung nicht über den Gehalt von Wahrnehmun-

17 Boghossian und Velleman argumentieren sogar, daß die Annahme von Farbdispositionen und von sensational properties (in den meisten Fällen) nicht mit der Phänomenologie der Farbwahrnehmungen übereinstimmt (vgl. Boghossian \& Velleman (1989): 94ff.). Denn geht man von der Existenz von farb-phänomenalen Eigenschaften des visuellen Gesichtsfeldes aus, dann sieht dies auch die einzigen, die uns phänomenal als Eigenschaften externer Objekte gegeben sind. Für subjektive Farbdispositionen ist phänomenal demnach kein Platz mehr, während repräsentational sie bereits aufgrund der Reflektanzeigenschaften nicht gebraucht werden. Die beste Schlußfolgerung ist somit wahrscheinlich, von einer Projektion der Farbphänomenalität auf die repräsentierten, objektiven Eigenschaften auszugehen. 
gen analysiert werden dürfen, so daß die Notwendigkeitsthese (NEC) abgelehnt und eine alternative Theorie der Qualia gefunden werden muß (vgl. Einleitung zu Byrne \& Hilbert (1997a): xxi-xxii); ${ }^{18}$ sondern die obige Argumentation hat auch plausibel gemacht, daß die Annahme eines Farbgehaltes für einen Dispositionalisten (oder Relationalisten) mit schwerwiegenden Problemen verbunden ist. Der einfachste Ausweg hieraus ist dann die Aufgabe der Ansicht, daß Farben über Farbwahrnehmungen definiert werden: mit einer objektivistischen Position als Resultat.

Der subjektivistische Dispositionalist kann jedoch ebenso versuchen, Farben nicht als repräsentierte oder detektierte, sondern bloß als phänomenal gegebene oder präsentierte Eigenschaften anzusehen. Dann sind Farben nicht mehr Bestandteil eines Wahrnehmungsgehaltes, sondern bestimmte, immer im Verbund mit Farbwahrnehmungen auftretende Eigenschaften (wie etwa die von Peacocke vorgeschlagenen sensational properties). Da deren Phänomenalität uns jedoch unmittelbar sinnlich und introspektiv zugänglich ist, scheint es angebrachter zu sein, sie entweder selbst mit den Farbqualia gleichzusetzen (McGinn?) oder sie wenigstens diese bestimmen zu lassen (Peacocke?). Somit werden also wiederum die phänomenalen Farbwahrnehmungstypen über die Farben analysiert (und nicht umgekehrt), wobei diesmal letztere keine objektiven, sondern subjektive Eigenschaften darstellen: es handelt sich folglich um einen Projektivismus. Zusammenfassend läßt sich also sagen, daß eine Definition der Farben über die Farbwahrnehmungen kein ontologisches Fundament erhalten kann: auch der Subjektivismus wird Farbwahrnehmungen über Farben bestimmen und somit eine unabhängige Analyse - im Sinne der Analysethese (ANA) - von den Farbeigenschaften anbieten müssen.

Der Projektivismus stellt somit die einzig mögliche, subjektivistische Theorie der Farben dar. Diese Position kommt der Grundauffassung des Farbsubjektivismus auch viel näher als eine relationalistische Version, da das Farbesein der betreffenden Eigenschaften direkt aus der Phänomenalität derselben hergeleitet wird, während die Farbdispositionen im Grunde selbst gar keine phänomenalen Eigenschaften sind, sondern nur über Farbqualia begrifflich definiert werden. Die Dispositionen gelten also nur deswegen als Farben, da sie eine logische Verknüpfung zu entsprechenden, phänomenalen Farbwahrnehmungen aufweisen. Den von den Projektivi-

18 Vgl. die Debatte zwischen Shoemaker (1995) und Harman ((1995a); (1995b)). 
sten als Farben angesehenen Eigenschaften kommt die Phänomenalität jedoch von sich aus zu: aus ( $\left.\mathrm{IND}_{\mathrm{P}}\right)$ folgt direkt ihr Status als Farben. Auch aus diesem Grund sollte der Projektivismus dem Dispositionalismus vorgezogen werden. Dahinter verbirgt sich natürlich der Umstand, daß der subjektivistische Dispositionalismus ohne Rückgriff auf Farben nicht erklären kann, warum bestimmte Sinneserfahrungen als Farbwahrnehmungen gelten. In diesem Abschnitt ist nun zwar die Unplausibilität einer gleichzeitig subjektivistischen und dispositionalistischen (oder relationalistischen) Farbtheorie bereits zu Genüge argumentativ gestützt worden. Aber es ist vielleicht angebracht, noch einige, weitere Argumente gegen diese Position zu besprechen, die sich in der Literatur finden lassen, auch wenn sich herausstellen wird, daß sie allesamt den subjektivistischen Dispositionalismus nicht wirklich gefährden können.

\subsubsection{Weitere mögliche Gegenargumente}

Selbst wenn der subjektivistische Dispositionaismus trotz seiner unglaubhaften Ontologie vertreten werden sollte, können sich eventuell einige zusätzliche Schwierigkeiten auftun. Ein erster Zweifel mag daraus herrühren, daß wir Farben anscheinend phänomenal nicht als Dispositionen wahrnehmen (John Campbell (1993) beschreibt diesen Disput, geht ihm jedoch mit seinem Primitivismus ganz aus dem Weg: 257f.). Johnston akzeptiert diese These und räumt somit eine Fehlerhaftigkeit unserer Farbrepräsentationen ein (Johnston (1992): 141). Auch darin ähnelt er den Farbobjektivisten, die ebenfalls davon ausgehen, daß die physikalisch beschreibbare Natur der Farben (ob als Reflektanzprofile oder -typen verstanden) uns nicht gegeben ist. Diese Konzession ist jedoch nicht schwerwiegend, da sie nur auf ein generelles Merkmal unserer Wahrnehmung hinzuweisen scheint. So sehen wir auch viele relationale Eigenschaften (wie Oben oder Unten) nicht als relationale; und die Illusion der kopflosen Frau zeigt ebenso, daß etwas nicht Wahrgenommenes nicht unbedingt auch etwas nicht Existierendes sein muß (vgl. Armstrong (1997): 60f.; sowie Shoemaker (1994b): 234). Einige Subjektivisten ziehen hieraus auch die Konsequenz, den Dispositionalismus zu vermeiden, indem sie entweder einen Projektivismus vertreten (vgl. Mackie (1976): 11) oder aber die ontologische Ebene erst einmal ganz 
ausklammern (vgl. Wright (1992): 138). Wieder andere leugnen eine Fehlerhaftigkeit der Phänomenalität:

\begin{abstract}
„There is no general obstacle to taking that appearance at face value. An object's being such as to look red [i.e., its disposition to look red - der Autor] is independent of its actually looking red to anyone on any particular occasion. [...] And there is no evident ground for accusing the appearance of being misleading. What would one expect it to be like to experience something's being such as to look red if not to experience the thing in question (in the right circumstances) as looking, precisely, red?“(McDowell (1985): 112)
\end{abstract}

Diese letzte Frage ist wohl kaum zu beantworten. Selbst die gegebene Analyse der Dispositionalität wird nicht zu einem anderen Ergebnis gelangen, as daß die Instantiierung einer Disposition genauso aussieht wie die Instantiierung ihrer Basiseigenschaft, welche die entsprechende Wahrnehmung hervorgerufen hat. Johnston weist zwar auf nicht-beständige, ,schimmernde" Farben hin, die unter anderem auf $C D$ s oder auf Ölschlieren zu sehen sind und als ein Beispiel für als dispositional wahrgenommene Farbeigenschaften dienen können sollen; aber diese Farben zeigen höchstens vielleicht eine Richtungs- und Beleuchtungsabhängigkeit, sicherlich jedoch nicht eine (noch so schwache) Geistabhängigkeit. Sie werden damit wohl als Farbillusionen eingestuft werden können, doch es ihre vermeintliche, subjektivistische Dispositionalität (die ja auf einer schwachen Geistabhängigkeit beruht) ist in den entsprechenden Wahrnehmungen alles andere als ersichtlich. Vor diesem Hintergrund kann also nicht ohne weiteres von einer Konzession der dispositionalistischen Theorie gesprochen werden. Boghossian und Velleman versuchen zwar noch, einen phänomenalen Unterschied zwischen dispositionalen und kategorialen Eigenschaften zu beschreiben, doch ihr Versuch ist wenig überzeugend (vgl. Boghossian \& Velleman (1989): 86).

Ihr Argument beruht auf dem Umstand, daß, wenn das Licht in einem dunklen Raum angeschaltet wird, die Farben der Gegenstände augenblicklich sichtbar werden. Wären nun Farben Dispositionen, dann sollten sie nicht automatisch sichtbar sein, sondern, wie das Licht selbst, ,angeschaltet" oder ,aufgeweckt" wirken; und ebenso, wenn das Licht wieder ausgemacht wird, sollten auch die Farben nicht sofort verschwinden, sondern 
„einschlafen“. Es ist alles andere als klar, wie dieses Argument zu verstehen ist. Der Punkt von Boghossian und Velleman scheint vielleicht der zu sein, daß die kausale Manifestierung einer Disposition immer ein zeitlicher Prozeß ist (wie auch das Lösen von Salz von Wasser seine Zeit braucht): doch Farben erscheinen uns, unter den entsprechenden Bedingungen, immer instantan vorhanden zu sein. Aber es ist ohne weiteres denkbar, daß die involvierten Kausalrelationen sich so schnell einstellen (insbesondere bei der bekannten Größe der Lichtgeschwindigkeit), daß wir dies bei unserer begrenzten zeitlichen Auflösung nicht bemerken können. Und zudem ist dieselbe zeitliche Verzögerung auch bei der Wahrnehmung kategorialer Eigenschaften zu erwarten: ja tatsächlich sind es ja diese, die die sinnliche Erkennung von Dispositionen ermöglichen. Aus phänomenologischer Sicht spricht also nichts gegen Farben als subjektive Dispositionen.

Auch ein weiteres Argument von Boghossian und Velleman ist wenig hilfreich, den Dispositionalismus (oder auch einen Objektivismus) in Verlegenheit zu bringen (vgl. Boghossian \& Velleman (1989): 86f.). Ihr Vorwurf lautet, daß von uns farbig gesehene Nachbilder offensichtlich nicht als Träger von Farbdispositionen in Frage kommen, da solche Instanzen materielle Objekte sein müssen (wie etwa ein Trinkbecher oder ein Briefkasten); und trotzdem werden die Nachbilder von uns als Träger der Farben repräsentiert. Eine Möglichkeit, um diesen Einwand zu entgehen, wäre es, die Repräsentiertheit von Nachbildern ganz zu leugnen, so daß diese gar nicht als Träger der Farbeigenschaften der gesehen werden (vgl. Bigelow, Collins \& Pargetter (1990): 281). Doch diese Lösung ist nicht zufriedenstellend, da Nachbilder uns räumlich lokalisiert erscheinen (wir sehen sie als in derselben Distanz vor uns befindlich wie diejenigen vorher wahrgenommenen Gegenstände, die für das Auftreten der Nachbilder verantwortlich sind) und somit eine Repräsentationalität der betreffenden Sinneserfahrung wohl kaum vermieden werden kann. Doch sie stellen für den Dispositionalisten (oder auch den Physikalisten) kein Problem dar, da sie als eine nicht-veridische Repräsentation erklärt werden können (vgl. Tye (1995): 108f.).

Ein weiteres Gegenargument wird von Broackes genannt. Er disktutiert eine dispositionale Farbeigenschaft, deren Instantiierung gleichzeitig immer die Disposition mit sich bringt, jeden möglichen Betrachter instantan 
zu töten, so daß es vor dem Tod nicht einmal mehr zu einer Farbwahrnehmung kommt. Die Farb- und die Tötungsdispositionen sind notwendigerweise koextensional. Doch dann ist es für ein Subjekt auch von vornehe rein möglich, die betreffende Farbe jemals wahrnehmen zu können: die betreffende Farbdisposition ist prinzipiell niemals manifestierbar (und nicht bloß kontingenterweise). Aber daß heißt eigentlich nichts anderes, als daß gar keine Farbdisposition vorliegt, woraus Broackes auf die Ungültigkeit des Dispositionalismus schließt (vgl. Broackes (1992): 442f.). Doch dieser Schluß ist nur dann möglich, wenn der betreffende Gegenstand auch wirklich als ein farbiger Gegenstand angesehen werden soll. Doch der Subjektivismus - und darum handelt es sich bei dieser Form des Dispositionalismus ja auch - muß (und wird) nicht behaupten, daß ein prinzipiell nichtwahrnehmbarer Gegenstand eine Farbe besitzt: ein nicht-sichtbarer Gegenstand bleibt farblos. Damit bleiben alle in diesem Abschnitt besprochenen Einwände gegen den subjektivistischen Dispositionalismus wirkungslos. Doch die im letzten Teilstück genannten, entscheidenden Gegenargumente haben weiterhin Bestand. Somit bleibt für einen Subjektivisten hinsichtlich der Farben nur der Projektivismus als Alternative übrig, wie es auch Keith Campbell sieht:

„Subjectivism comes in at least three forms, all of which must be, in one way or another, projectivist. It is of the essence of every subjectivism to hold that whatever does literally bear the colour properties, it is not the bodies (or the surfaces, or the light sources) that seem to. So appearances must deceive. [...] All subjectivisms are projectivist, so they are all error theories." (K. Campbell (1993): 265)

\subsection{Projektivismus}

Der Projektivismus geht davon aus, daß die phänomenalen Farbwahrnehmungstypen über die in ihnen präsentierten Farben individuiert werden können (natürlich hängen die Farbtatsachen trotzdem ontologisch von den Farbwahrnehmungen ab). ${ }^{19}$ Diese phänomenalen Farben sind uns wieder-

19 Der Projektivismus stellt gleichermaßen die bei weitem unklarste und die am wenigsten ausgearbeitetste Theorie der Farben dar. Innerhalb der Literatir erlauben 
um introspektiv zugänglich und entsprechen dem phänomenalen Aspekt der Intuitiven Farbkonzeption. Wie die bisherigen Überlegungen zum Subjektivismus allgemein gezeigt haben, werden die Farben jedoch nicht von den Farbwahrnehmungen repräsentiert oder detektiert, sondern liegen immer nur präsentiert vor, wenn eine entsprechende Sinneserfahrung auftritt. Die visuellen Sinneserfahrungen repräsentieren zwar bestimmte Eigenschaften der externen Gegenstände (wie Formen oder auch Reflektanzen), doch die Farbigkeit wird durch das Gehirn und den Geist auf die Welt projeziert oder der Welt auferlegt. Projektion ist keine Repräsentation, sondern eine Präsentation.

\begin{abstract}
„A possible view about all of these cases is the 'projectivist' view that in our perceptual experience we in some sense project what are in fact nonintentional features of our experiences, i.e., qualia, onto the states of affairs these represent. So when I revel in the blue of the sky, the quality to which I am responding aesthetically is really a feature of my experience, which I mistakenly take to be instantiated in front of me." (Shoemaker (1990): 101f.)
\end{abstract}

Nun scheinen aber die von unseren Farbwahrnehmungen repräsentierten Objekte dabei farb-phänomenale Eigenschaften aufzuweisen: wie sehen offentsichich die Gegenstände in der externen Welt als Träger der Farbeigenschaften. Doch in der objektiven Realität selbst gibt es keine solcherart farbigen Objekte. Folglich stellt der Projektivismus eine error theory dar. Eine wesentlicher Bestandteil der gewöhnlichen Ansicht über Farben, wie sie uns allein durch unseren visuellen Sinn vermittelt wird, ist falsch. Diese Idee findet sich - laut Mackies Interpretation - bereits bei Locke, der sie auf eine ganze Reihe sogenannter sekundärer Qualitäten ausgeweitet hat:

„We... commonly ascribe to material things colours as we see colours, as they occur as elements in our experiential content, and again heat, cold, roughness, and so on as we feel them; we ascribe tastes as we taste them to bits of food and to liquids, smells as we smell them to spatial regions; and I think of the ticking sound as I hear it as coming to me from the clock. But this is all a mistake, a systematic

sowohl ihre Darstellungen als auch die der gegen sie gerichteten Argumente kein einfaches Verständnis der Position. Aus diesem Grund lassen sich die folgenden Ausführungen nicht immer so klar strukturieren, wie es eigentlich wünschenswert wäre. 
error. All that is out there in reality is the shape, size, position, number, motionor-rest, and solidity, which occur as properties both of large-scale things and of their minute parts.“ (Mackie (1976): 11)

Es spricht vielleicht nicht unbedingt für den Projektivismus, daß er Farbigkeit wahrscheinlich auf eine sehr ähnliche Weise wie Geschmack oder Geruch auffassen muß, da nicht nur biologisch betrachtet einige wesentliche Unterschiede bestehen, sondern gerade auch im alltäglichen Umgang mit Gegenständen. Denn obwohl (oder gerade weil) unser Geruchs- oder Geschmackssinn viel feingradiger diskriminieren kann, spielt er - ganz im Gegensatz zum Farbensehen - in der Individuation von Gegenständen keine herausragende Rolle. Doch dies ist ein generelles Problem vom Subjektivisten, welches im späteren Vergleich mit den objektivistischen Positionen an Bedeutung gewinnen wird. Da unsere Farburteile somit nicht mehr durch objektive Tatsachen über die wahrgenommenen Gegenstände in der Welt wahrgemacht werden können, wir ihnen aber trotz allem im alltäglichen Umgang einen Wahrheitswert zuerkennen, muß eine besondere Semantik der Farbzuschreibungen entwickelt werden. Die übliche Strategie ist es, Äußerungsbedingungen für Farburteile zu formulieren, die sich nicht auf einen realistischen und robusten, sondern auf einen anti-realistischen und epistemischen Wahrheitsbegriff stützen (vgl. Wright (1992): Kap. 2; Boghossian (1989); Boghossian \& Velleman (1989): 100ff.). Zudem ist es wohl durch die systematische Fehlerhaftigkeit keine Verletzung eines principle of charity, wenn die Bedeutungen von Aussagen innerhalb einiger, bestimmter Diskurse anti-realistisch gedeutet werden:

„First, a principle of charity applies primarily to a language, or other representational system, taken as a whole; and so, when rightly understood, such a principle is perfectly consistent with the possibility that large regions of the language should rest on widespread and systematic error. Second, what a principle of charity recommends is, not that we should avoid attributing widespread error at all costs, but that we should avoid attributing inexplicable error. And the error that a Galilean view of colour entails is not inexplicable; it can be explained precisely as an error commited through projection - that is, through the misrepresentation of qualities that inhere in the visual field as inhering in the objects that are therin represented.“ (Boghossian \& Velleman (1989): 97) 
Auf einen wichtigen Punkt - gerade im Zusammenhang mit dem letzten Satz dieses Zitates - sollte hier jedoch noch einmal besonders hingewiesen werden. In der Farbendebatte wird üblicherweise einfach davon ausgegangen, daß auch für den Subjektivismus die Farbeigenschaften Teil des Gehaltes der betreffenden Sinneserfahrungen sind. Doch dies kann, wie bereits argumentiert worden ist, aus theoretischer Sicht nicht zutreffend sein. Subjektive Farben werden nicht repräsentiert. ${ }^{20}$ Der in der Projektion liegende systematische Fehler betrifft also nicht den Umstand, daß Gegenstände wirklich von unseren Farbwahrnehmungen systematisch als Farbträger fehlrepräsentiert werden, sondern vielmehr den Umstand, daß die Sinneserfahrungen uns den Eindruck vermitteln, es läge scheinbar eine Repräsentation vor. Subjektive Farben können nicht Bestandteil eines Wahrnehmungsgehaltes sein; aber sie können uns sinnlich so präsentiert werden und an Gegenständen lokalisiert erscheinen, so daß wir fälschlicherweise wahrzunehmen glauben, sie befänden sich tatsächlich an den Objekten selbst. Unsere Farbwahrnehmungen repräsentieren nur Reflektanzeigenschaften der externen Gegenstände. ${ }^{21}$ Diese repräsentierten Eigenschaften erschei-

20 Peacocke, dessen Position irgendwo zwischen einem Dispositionalismus und einem Wörtlichen Projektivismus einzuordnen ist, gibt sogar ein Beispiel dafür an, daß eine subjektive, phänomenal präsentierte Farbe vorliegt, ohne daß der wahrgenommene Gegenstand als der Träger dieser Farbe gesehen oder repräsentiert wird. Wenn man durch eine rotgefärbte Folie oder Glasplatte eine weiße Wand betrachtet, dann sieht die Wand immer noch weiß aus, auch wenn unser visuelles Gesichtsfeld in gewisser Weise ,,rötlich“ ist (für Peacocke handelt es sich bei dieser Rötlichkeit um den Farbqualia ähnlichen sensational properties, die unten im Abschnitt über den Wörtlichen Projektivismus besprochen werden - vgl. Peacocke (1984): 412; Fn. 10).

$21 \mathrm{Daß}$ sie dies tun, läßt sich vor dem Hintergrund der bereits entwickelten, direktrealistischen Gehaltstheorie nicht vermeiden - auch nicht für den Subjektivisten. Und wie sollte auch sonst die biologische Funktionalität der visuellen Wahrnehmungen zufriedenstellend erklärt werden können: daß zum Beispiel Gegenstände nur aufgrund von Unterschieden in ihrer Farbigkeit diskriminiert werden können? Shoemaker argumentiert ebenfalls dafür, daß unsere Farbwahrnehmungen auf alle Fälle diejenigen objekiven Merkmale von externen Gegenständen repräsentieren, welche die Objektivisten als Farben ansehen (vgl. Shoemaker (1990): 115f.). Er teilt sogar die Ansicht der Projektivisten, daß es noch einen zweiten Gehalt gibt, der die Farbeigenschaft den externen Objekten zuspricht und gleichzeitig niemals zutreffend sein kann. Doch auch seine Sprechweise kann, nach dem hier entwickelten Argument, nicht wörtlich genommen werden. 
nen uns dabei jedoch nicht als Reflektanzen, sondern werden mit einer den Farben zugesprochenen Phänomenalität präsentiert. In diesem Sinne ist es aus einer theoretischen Perspektive nicht zutreffend, wenn Projektivisten davon sprechen, daß Farben von unseren Farbwahrnehmungen repräsentiert werden (vgl. etwa Boghossian \& Velleman (1989): Fn. 4; 96; 100).

Der Subjektivist kann sagen, daß die Farben präsentiert und die Reflektanzen präsentiert werden, und wahrscheinlich auch noch, daß die Reflektanzen vermittels der Phänomenalität der Farben repräsentiert werden. Aber unsere intuitive Meinung, daß Farben selbst repräsentiert werden, muß der Subjektivismus für falsch erklären. Es fällt einem nicht immer ganz leicht, diese beiden Redeweisen auseinanderzuhalten, gerade da Repräsentation und Präsentation eng miteinander zusammenhängen zu scheinen (insbesondere, wenn man das Präsentierte als eine Art von „Gegebenheitsweise“" oder ,engem Gehalt“ auffaßt). Und in den meisten Fällen wird eine entsprechende Ungenauigkeit auch keine bemerkenswerten Auswirkungen haben. Docht trotzdem sollte man sich über den Unterschied und die Gefahr der Verwechslung bewußt werden. Der mit unseren Sinneserfahrungen verbundene Fehler liegt demnach nicht darin, daß immer Farbillusionen oder Farbhalluzinationen vorlägen. Vielmehr besteht der systematische Fehler darin, daß Gegenstände uns systematisch als Instanzen von Farben erscheinen, weil die Natur der repräsentierten Eigenschaften falsch präsentiert wird: die Phänomenalität der Farben wird von unseren Wahrnehmungen fälschlicherweise auf die extern instantiierten Reflektanzeigenschaften übertragen, oder eben auf diese projeziert. So kommt es, daß wir Gegenstände als farbig zu sehen scheinen und die entsprechenden, naiven - und laut Projektivismus falschen - Überzeugungen über Farbsachverhalte erlangen. Vor diesem Hintergrund kann, wörtlich genommen, nicht alles stimmen, was Boghossian und Velleman schreiben, um sich von einem Adverbialismus abzugrenzen.

„One might be tempted to dissolve the conflict between the [projectivist] view and the [objectivist] view of colour experience by rejecting a presupposition that they share. Both sides of the conflict assume that the properties mentioned in our descriptions of visual experience are properties that such experience represents objects as having. The only disagreement is over the question whether the colour properties that are thus attributed to objects by visual experience are properties that the objects tend to have. One might claim, however, that visual experience 
does not attribute properties to objects at all; and one might bolster one's claim by appeal to a theory known as adverbialism. According to adverbialism, the experience of seeing a thing as red is an event modified by some adverbial property - say, a seeing event that proceeds red-thing-ly. Not all adherents of adverbialism are commited to denying that such an experience represents an object as having a property; but adverbialism would indeed be useful to one who wished to deny. $[\ldots]$

Our view is that this extreme version of adverbialism does unacceptable violence to the concept of visual experience. Seeing something as red is the sort of thing that can be illusory or veridical, hence the sort of thing that has truth-conditions, and hence the sort of thing that has content. The content of this experience is that the object in question is red; and so the experience represents an object as having a property, about which we can legitimately ask whether it is a property that objects so represented really tend to have.“ (Boghossian \& Velleman (1989): Fn. 4)

Doch es ist wichtig, Farben nicht als repräsentierte, sondern nur als präsentierte Eigenschaften anzusehen, deren phänomenale Natur innerhalb der Sinneserfahrungen den repräsentierten Reflektanzeigenschaften auferlegt wird. Farben primär als subjektive, phänomenal erscheinende Eigenschaften anzusehen, heißt eben nicht, sie als repräsentierte Merkmale aufzufassen. So kann gerade der zweite Absatz des Zitates eigentlich nur von einem Objektivisten in voller Stärke behauptet werden. Allein für diesen werden Farben (als Reflektanzen verstanden) repräsentiert, können objektive Tatsachen als Wahrheitsbedingungen dienen und sind Fehlrepräsentationen von Farben möglich. In diesem Sinne betrifft der systematische Fehler auch nicht unbedingt den repräsentationalen Aspekt der Wahrnehmungen, sondern eher den phänomenalen. Die ontologische Natur der repräsentierten Eigenschaften ist uns nicht transparent gegeben, so daß die uns zugängliche, phänomenale Natur der präsentierten, subjektiven Farben deren Platz einnehmen kann. Das Resultat ist eine eigenartige Verwechslung der beiden Eigenschaften (oder der beiden Naturen): die objektiven, repräsentierten Eigenschaften erscheinen auch als phänomenal. Genau deshalb ist die allen Farbtheorien gemeinsame Grundthese (IND) nur über Farbpräsentation oder Farberscheinung formuliert worden.

Natürlich liegt Übereinstimmung darüber vor, daß Farben in unseren Sinneserfahrungen an externen Gegenständen lokalisiert zu sein scheinen und daß deshalb die naiv begründete Intuitive Farbkonzeption die Reprä- 
sentiertheit der Farben miteinschließt. Aber die theoretischen Überlegungen erlaubt es nur dem Objektivisten, die damit verbundenen Merkmale des repräsentationalen Aspektes der Intuitiven Farbkonzeption für Farben aufrechtzuerhalten. Der Projektivmus muß akzeptieren, daß unser gewöhnliches Verständnis von Farben zwar deren Repräsentiertheit und externe Instantiierbarkeit beinhalte, doch daß seine Theoretisierung der Farbphänomene diese repräsentationalen Merkmale allesamt fallenlassen muß. Ein Objekt als rot zu sehen, kann für ihn weder illusorisch, noch veridisch sein; vielmehr werden Farben einfach immer fälschlicherweise als repräsentierte Eigenschaften präsentiert. Die von Boghossian und Velleman gewählte Redeweise sollte somit mit Vorsicht genossen werden. Auch wenn es in vielen Situationen hilfreich sein mag, von zwei verschiedenen Gehalten von Farb wahrnehmungen zu sprechen - einem normalen, repräsentationalen und einem, der systematisch falsch ist -, sollte dies möglichst vermieden werden: die projektivistisch verstandenen Farbwahrnehmungen besitzen nicht den von uns ihnen üblicherweise zugesprochenen Farbgehalt, sondern nur einen mit der Farbphänomenalität, ,angereicherten“ Reflektanzgehalt.

Anhand des ontologischen Status der subjektiven, phänomenalen Farben können nun Varianten der projektivistischen Position differenziert werden: entweder sind die subjektiven Farben intern instantiiert, oder aber sie haben faktisch gar keine Instanzen. Die erste Position entspricht dem Wörtlichen, die beide Position dem Bildlichen Projektivismus. Diese Bezeichnungen sind von Shoemaker geprägt worden, bei dem sich auch die entsprechende Unterscheidung findet (wobei der Ausdruck „Repräsentation“ im folgenden Zitat, wie die obigen Ausführungen nahelegen, nicht allzu wörtlich verstanden werden sollte).

„So let us distinguish literal projectivism, which says that our experience represent external things as having properties that in fact belong only to experiences, and figurative projectivism, which says that in virtue of properties they do have our experiences represent external objects as having properties that in fact belong to nothing." (Shoemaker (1990): 116)

In der Literatur finden sich noch andere Bezeichnungen und Klassifikationen. Keith Campbell bezeichnet den Bildlichen Projektivismus als eine 
full-scale error theory; den Wörtlichen Projektivismus unterteilt er zudem noch in eine reduktive und eine dualistische Variante, je nach dem, ob die betreffenden, intern instantiierten Eigenschaften naturalisierbar sind oder nicht (vgl. K. Campbell (1993): 265f.). Bei Byrne und Hilbert heißt die projektivistische Position im allgemeinen „Eliminativismus“, weil der Theorie entsprechend keine externen, physikalischen Objekte farbig sind und Farben somit aus der objektiven Realität „eliminiert“ werden (vgl. Einleitung zu Byrne \& Hilbert (1997a): xx). Doch es ist üblicher, diesen Ausdruck nur für den Bildlichen Projektivismus zu verwenden, da dieser als einziger gar keine Art von Farbtatsachen als existent annimmt. So kommt es, daß der eliminative Bildliche Projektivismus oftmals auch nonfactualism benannt wird. Die beiden möglichen Hauptvarianten des Projektivismus - der Bildliche und der Wörtliche - sollen nun in den nächsten Abschnitten nacheinander abgehandelt werden. Doch davor ist es angebracht, sich die generellen Schwierigkeiten einer projektivistischen Position vorzunehmen

\subsubsection{Argumente gegen den Projektivismus im allgemeinen}

Das generelle Problem für einen Projektivismus ist natürlich die Zugabe eines systematischen Fehlers hinsichtlich von Farbwahrnehmungen. Da die These (REP) nicht aufrechterhalten werden kann, liegt eine systematische Veridizität vor: Farben sind keine objektiven, intrinsischen, externen Eigenschaften, die repräsentiert werden und das Auftreten unserer Farbwahrnehmungen erklären können. Dieser berechtigte Vorwurf zieht sich durch alle kritischen Kommentare; er ist jedoch an sich noch nicht entscheidend, da auch der Objektivismus aller Wahrscheinlichkeit nach Abstriche bei der Intuitiven Farbkonzeption machen muß, wenn er die These (PHE) nicht wird vertreten können. Es kann höchstens die Art dieses Fehlers problematisch werden, vor allem, wenn es sich dabei um einen kategorialen Fehler handelt, wie er bereits von Descartes und Berkeley thematisiert worden ist.

Darüberhinaus hat der Subjektivismus den großen Nachteil, daß er an für sich genommen wenig Attraktivität besitzt, sondern nur als eine letzte Ausweichsmöglichkeit in Betracht gezogen wird. So haben schon die Philosophen der empiristischen Tradition nur aufgrund der wissenschaftlichen 
Erkenntnisse ihrer Zeit sich gezwungen gefühlt, sich vom Farbobjekvitismus abzuwenden; und auch zeitgenössische Vertreter des Projektivismus haben diese Position erst deswegen ergriffen, weil alle anderen Alternativen für eine Theorie der Farben ihnen zu problematisch erschienen sind (vgl. Boghossian \& Velleman (1989) und (1991)). Dies hat Keith Campbell dazu veranlaßt, den Subjektivismus wie folgt zu beschreiben:

\begin{abstract}
„All subjectivisms are projectivist, so they are all error theories. That is by itself not fatal. But error theories are fall-back positions. They do not recommend themselves as inherently plausible; they are positions to which one is forced, reluctantly, by the untenability of the alternatives. [...] Indeed, error theory about colour is not just a fall-back option; it is a desperation option. Just how desperate an option it is can be glimpsed from a review of each of its variants." (K. Campbell (1993): 263)
\end{abstract}

Johnston versucht nun zusätzlich, einen bestimmten Motivationsgrund für den Projektivismus zu entfernen. Dabei handelt es sich um die folgende, einfache Überlegung: da Farben weder eine physik-immanente, noch eine dispositionale Natur in unseren Sinneserfahrungen offenbaren, liegt es nahe, Farben nicht als solche Eigenschaften anzusehen, sondern stattdessen als phänomenale, da uns die Farbphänomenalität in den Wahrnehmungen gegeben ist. Dagegen wendet Johnston nun ein, daß es doch Farbtatsachen gibt, die als subjektivistisch-dispositional (oder relational) gesehen werden: sogenannte ,schimmernde“ Farben, wie sie sich auf Ölflecken oder CDs zeigen, und zwar ganz in Abhängigkeit von der vorherrschenden Beleuchtung und der Position des Betrachters. Konsequenterweise müßte der Projektivist wenigstens diese Farben in der Welt lokalisieren (vgl. Johnston (1992): 141f.). Doch der Einwand trifft den Projektivismus nicht. Johnstons Alternativvorschlag ist selbst nicht der beste: auch eine dispositionale Theorie kann (will sie selbst kein Projektivismus werden) die Phänomenalität der Farben voraussichtlich nicht erfaßen. Und ganz davon abgesehen zeigen die ,schimmernden Farben“" zwar eine Abhängigkeit von der Blickrichtung und der damit verbundenden Position des wahrnehmenden Subjektes, doch dies genügt bei weitem nicht, um einen subjektivistisch-dispositionalen (oder relationalen) Charakter erkennen zu lassen (wenn es sich nicht sogar um Fälle von Farbillusionen handelt): denn eine dafür wesent- 
lich erforderliche Geistabhängigkeit ist alles andere als offensichtlich gegeben.

Armstrong hingegen weist auf ein wirklich schwerwiegendes Problem für alle projektivistischen Positionen hin: die Projektion der Farbigkeit auf die Realität zu exakt und mit einer zu großen, intersubjektiven Übereinstimmung verbunden, daß es sehr unwahrscheinlich wäre, wenn die Farbigkeit nicht doch auf objektiven Tatsachen in der Welt beruhen würde (vgl. auch Armstrong (1993): 272).

„I am inclined to think that supporters of the projection theory have not really thought it through. The other instances of projection that are cited as precedents are various strong attitudes, whether of attraction or revulsion, which, as we all experience, seem to invest things or events with an objective correlate of the attitude. Hume, in a wonderful conceit, spoke of the mind's disposition to spread itself on external objects. [...]

But this spreading is surely very vague and imprecise. It creates a good or an evil aura around things, but it is something hard to pin down. In sharp contrast, the boundaries of the colours of physical things are in great majority of cases very exact. Nothing is easier than to get noncollusive agreement between different perceivers that one colour is found up to a certain line of a surface and another colour beyond it. It is impossible not to think that at that point there is an objective change in the surface. The projection story must be that the eye is able to pick up a physical differentiation at this boundary (without perceiving it as a physical differentiation!), and then clothe the difference with colour qualities that are instantiated in the mind only, colours which the mind precisely but erroneously substitutes for the physical difference. Not self-contradictory, perhaps, but that seems about the best thing that can be said for the story!" (Armstrong (1997): 59f.)

$\mathrm{Ob}$ und wie der Projektivismus dieses Problem vielleicht doch umgehen kann, soll erst im Schlußkapitel behandelt werden. Bis dahin wird dieser allgemeine Einwand erst einmal gegen diese Position im allgemeinen Bestand haben. Doch auch die einzelnen, projektivistischen Positionen im besonderen zeigen entscheidende Mängel. 


\subsubsection{Der Wörtliche Projektivismus}

Dem Wörtlichen Projektivismus (literal projectivism) zufolge sind Farben nicht nur introspektiv zugängliche, phänomenale Eigenschaften, sondern zudem auch tatsächlich von Zuständen des Subjektes instantiiert. Hierbei handelt es sich ganz allgemein um eine (nach Wrights Terminologie) antirealistische Auffassung über die Farbtatsachen. Zudem ist in dem allgemeinen Abschnitt über den Subjektivismus bereits gezeigt worden, daß diese Position - ähnlich der Sinnesdatentheorie - eine wechselseitige, ontologische Abhängigkeit zwischen Farbtatsachen und Farbwahrnehmungen behaupten muß: es können keine Farbtatsachen ohne entsprechende, gleichzeitig auftretende Farbwahrnehmungen existieren, und umgekehrt. Die naheliegendste Möglichkeit, solche Farben zu bestimmen, ist es, sie einfach mit den von den Wahrnehmungen instantiierten Farbqualia gleichzusetzen. ${ }^{22}$ So wird diese Position vor allem von Shoemaker verstanden (vgl. Shoemaker (1994b): 231; und (1990): 116]. Demnach lautet eine mögliche Formulierung der Hauptthese des Wörtlichen Projektivismus: ${ }^{23}$

$\left(\mathrm{WP}_{\mathrm{Q}}\right) \quad P_{\mathrm{i}}:=F_{\mathrm{i}}$-phänomenales Farbquale $Q_{\mathrm{i}}$.

Diese Form des Projektivismus ist nicht nur phänomenologisch betrachtet nicht sehr überzeugend, sondern auch aus ontologischer Sicht bereitet sie einige Schwierigkeiten. Da Farben uns offensichtlich als Eigenschaften der räumliche lokalisierten und ausgedehnten Gegenstände in der Außenwelt präsentiert werden, ist es nur schwer nachvollziehbar, wie solche Charakte-

22 Die Farbqualia dürfen dabei natürlich nicht repräsentationalistisch bestimmt werden, da dies automatisch zu einem Objektivismus $\mathrm{SEC}_{\mathrm{NEC}}$ führen würde, da die mit den Farben identifizierten Qualia auf einmal rein externalistisch durch objektive Faktoren bestimmt wären.

23 Es ist nicht ganz klar, ob diese Position wirklich vertreten wird. Die Vorschläge von Moreland Perkins und Brian O'Shaughnessy scheinen in die Nähe einer solchen Theorie zu kommen, doch wahrscheinlich handelt es sich eher um Abwandlungen eines Indirekten Realismus (vgl. unten; sowie K. Campbell (1993): 265). Wenn der subjektivistische Dispositionalismus tatsächlich aufgegeben werden muß, dann ist es sehr wahrscheinlich, daß McGinn diese Variante des Projektivismus akzeptieren wird, da auch er dazu neigt, Farbtatsachen mit den Farberscheinungen gleichzusetzen (vgl. McGinn (1983): 6). 
ristika in Wirklichkeit den Wahrnehmungen selbst zukommen sollen. Zwar können Farben uns vielleicht nur vermittels Farbqualia introspektiv zugänglich sein; aber erstere und letztere scheinen trotzdem fundamental unterschiedliche Instanzen zu haben: einerseits physikalische und anderseits mentale (vgl. auch Shoemaker (1990): 117). Diese Überlegungen haben bereits Descartes und Berkeley dazu bewegt, zu argumentieren, daß in diesem Fall von einer Projektion sinnvollerweise gar nicht ausgegangen werden kann. Denn mentale Eigenschaften auf physikalische Gegenstände zu projezieren, kommt einem kategorialen Fehler gleich, den unsere Farb wahrnehmungen unmöglich begehen können. In neuerer Zeit findet sich ein ähnlicher Vorwurf bei Shoemaker wieder:

„I am looking at a book with a shiny red cover. The property I experience its surface as having, when I see it to be red, is one that I can only conceive of as belonging to things that are spatially extended. How could that property belong to an experience or sensation? Remember that an experience is an experiencing, an entity that is 'adjectival on' a subject of experience. It seems no more intelligible to suppose that a property of such an entity is experienced as a property of extended material objects than it is to suppose that a property of a number, such as being prime or being even, is experienced as a property of material things." (Shoemaker (1994b): 231)

Somit scheint die Projektion nicht bloß einen systematischen, sondern sogar einen kategorischen Fehler zu beinhalten: die auf physikalische Gegenstände in der Außenwelt projezierten, mentalen Farbeigenschaften können von diesen externen Objekten prinzipiell gar nicht instantiiert werden; und es ist sehr unwahrscheinlich, daß unsere Wahrnehmungen solche kategorischen Fehler machen können. Boghossian und Velleman versuchen nun, diesen Einwand abzuschwächen, indem sie auf ein Beispiel von Wittgenstein hinweisen, in welchem die Möglichkeit einer ähnlichen Projektion angedeutet wird (vgl. Boghossian \& Velleman (1989): 99f.). Üblicherweise empfinden wir Schmerzen nicht als eine Qualität der externen Ursache: nicht die Stecknadel ist schmerzhaft oder schmerzlich, sondern der Schmerz selbst. Aber es ist vorstellbar, daß Schmerzempfindungen, nach den entsprechenden Veränderungen in der Umwelt, nur noch durch die Berrührung bestimmter Oberflächen in unserer Umgebung (von Pflanzen oder Steinen etwa) hervorgerufen werden. Wittgensteins Intuition ist nun 
die, daß man in diesem Fall von Schmerzflächen (oder -flecken) sprechen kann, genauso, wie man von entsprechenden Farbflächen redet; und die Schmerzflecken können für uns ebenso von einiger Bedeutung für die Individuation und Wiedererkennung von ihren Trägern sein (vgl. Wittgenstein (1984): § 312). Diesem Fall nach scheint es also möglich zu sein, daß phänomenale Eigenschaften nicht nur als Eigenschaften von mentalen Zuständen, sondern auch als Eigenschaften von externen Gegenständen sinnlich erfahren werden können. Und auch hier läßt es sich denken, daß der systematische Fehler der Projektion gerade darin besteht, die Schmerzflecken fälschlicherweise als Charakteristika der Objekte in der Außenwelt wahrzunehmen.

Hierauf kann man nun erwidern, daß es nicht klar ist, ob zum einen die Intuition wirklich ganz ohne jede Modifikation Bestand haben können wird, und ob zum anderen auch nach einer solchen Umdeutung oder Veränderung sie immer noch das erwünschte Resultat mit sich bringt und den Einwand von Shoemaker abschwächt. Denn es ist wahrscheinlich doch zu erwarten, daß sich, wenn die von Wittgenstein beschriebene Situation eintritt, auch die Phänomenalität der Schmerzempfindungen entscheidend verändern wird. Insbesondere wird ein räumlicher oder repräsentationaler Aspekt hinzutreten müssen, damit die Lokalisierung der Schmerzflecken außerhalb des Körpers in der Außenwelt ermöglicht werden kann. Die resultierenden Schmerzwahrnehmungen werden jedoch, aufgrund ihrer größeren Komplexität, aller Voraussicht nach eine ganz veränderte Schmerzphänomenalität zeigen. Insbesondere werden den Schmerzeigenschaften die Merkmale des repräsentationalen Aspektes zugesprochen werden müssen: also Repräsentiertheit, Objektivität, Externalität, Intrinsität und Erklärungskraft. Erst dann kann eine Analogie mit der Farbphänomenalität gegeben sein. Doch auf der einen Seite ist es nicht ganz klar, ob dies der Schmerz- oder Tastsinn leisten kann, da er faktisch eben nicht distale Reize detektiert und keinen kontinuierlichen Raum repräsentieren kann (vgl. vgl. den Abschnitt über die Möglichkeit von Farbempfindungen. Und auf der anderen Seite zeigt die erforderliche Veränderung der Phänomenalität ganz deutlich, daß ein wesentlicher, kategorialer Unterschied zwischen mentalen und physikalischen Trägern von Eigenschaften besteht. Der Einwand von Shoemaker - sowie Descartes und Berkeley - hat folglich weiterhin Bestand. 
Zudem kann der mittels $\left(\mathrm{WP}_{\mathrm{Q}}\right)$ spezifizierte Wörtliche Projektivismus keine zufriedenstellende Erklärung für die mit der Projektion verbundene Fehlerhaftigkeit liefern. Es wird insbesondere fraglich, warum die Farbqualia unbedingt mit den Farbeigenschaften gleichgesetzt werden sollen, da sie üblicherweise von uns begrifflich deutlich voneinander getrennt werden. Diese Variante des Wörtlichen Projektivismus scheint damit in Wirklichkeit nichts anderes - oder wenigstens nicht mehr - zu sein als ein Bildlicher Projektivismus, welcher davon ausgeht, daß Farbtatsachen faktisch gar nicht existieren. Darüberhinaus kann der Subjektivist vielleicht auch nicht davon ausgehen, daß die phänomenalen Eigenschaften von Wahrnehmungen in diesen präsentiert sind. Denn Überlegungen zur Introspektion auf Sinneserfahrungen legen nahe, daß, nimmt man Qualia als intrinsische Eigenschaften derselben an, diese uns nicht introspektiv zugänglich sein können, da Introspektion dann ein Akt des ,inneren Wahrnehmens“ der betreffenden mentalen Zustände sein muß. Doch ein solches Wahrnehmungsmodell ist im Grunde nur mit einer Theorie verträglich, die Sinnesdaten (oder ähnliche Entitäten) postuliert (vgl. Shoemaker (1994c); (1994a): 214ff.).

Werden die Farbqualia dagegen als relationale Eigenschaften der Wahrnehmungen angesehen, ergeben sich - wenn es sich um Relationen zu den distalen Reizen, den externen Objekten selbst, handelt - dieselben Probleme wie für den relationistischen Subjektivismus. Und zudem ist in diesem Fall wahrscheinlich der Objektivismus ${ }_{\mathrm{NEC}}$ die plausiblere Alternative, da er eventuell auch den repräsentationalen Aspekt einfangen kann. Es bleibt noch die Möglichkeit, Qualia als Relationen zu proximalen Reizen anzusehen (oder auch etwa als durch die engen, funktionalen Rollen der betreffenden Zustände bestimmte Eigenschaften). Diese Variante ist für einen Wörtlichen Projektivisten zwar plausibler, aber es bleibt immer noch der von Shoemaker formulierte Einwand hinsichtlich des kategorialen Unterschiedes zwischen Eigenschaften von mentalen Zuständen und physikalischen Gegenständen bestehen. Zudem ist immer noch die genaue Relation zwischen den Farbqualia und den repräsentierten Eigenschaften unklar; aber es ist vorstellbar, daß es sich bei den Farbqualia um eine Art von Gegebenheitsweise handeln könnte (vgl. Shoemaker (1990): 103f.; 118). Weitere Überlegungen $\mathrm{zu}$ der durch $\left(\mathrm{WP}_{\mathrm{Q}}\right)$ spezifizierten, projektivistischen Position sollen jedoch bis zu dem Kapitel über den Vergleich von Farbob- 
jektivismus und Farbsubjektivismus zurückgestellt werden.

Es gibt jedoch für den Projektivisten noch eine ganz andere Alternative: und zwar Farben als Eigenschaften des visuellen Gesichtsfeldes - als sensational properties, wie sie Peacocke nennt - anzusehen. Es ist jedoch nicht ganz klar, wie diese sinnlichen Eigenschaften aus ontologischer Sicht zu verstehen sind. Vor allem ist es wichtig, den Träger dieser Charakteristika zu identifizieren. In seinen früheren Texten wechselt Peacocke bei der Zuschreibung noch zwischen dem Wahrnehmungszustand und dem visuellen Gesichtsfeld hin und her, wobei die Betonung eindeutig auf ersteren $\mathrm{zu}$ liegen kommt. So definiert der die sinnlichen Eigenschaften dort noch als die nicht-repräsentationalen, mentalen Eigenschaften der Wahrnehmungen, ganz den Qualia gleichend:

„Corresponding to the historical distinction between sensation and perception, we can draw a distinction between sensational and representational properties of experience. Representational properties will be properties an experience has in virtue fo features of its representational content; while sensational properties will be properties an experience has in virtue of some aspect - other than its representational content - of what it is like to have that experience." (Peacocke (1983): 5)

Bevorzugt man diese Lesart, handelt es sich wiederum nur um einen etwas anders formulierten Wörtlichen Projektivismus, der Farben mit den Farbqualia identifiziert (da es keine alternativen phänomenalen und introspektiv zugänglichen Eigenschaften der Wahrnehmungen gibt). Doch in den späteren Überarbeitungen dieser These wird es deutlich, daß Peacocke die sinnlichen Eigenschaftenn lieber als in Wahrnehmungen präsentierte Merkmale des visuellen Gesichtsfeldes interpretieren möchte: und nicht mehr als mentale Eigenschaften der Wahrnehmungen selbst (vgl. auch die Einleitung zu Byrne \& Hilbert (1997a): xx-xix; Fn. 23).

„When a normal human sees a red object in daylight, there is a certain property possessed by the region of his visual field in which that object is presented to him. This property we can label 'red'": the canonical form is that region region $r$ of the visual field is red in token experience $e$. [Red' is] purely a property of the 
visual field, rather than a property the experience has in virtue of representing the world as being a certain way.“ (Peacocke (1984): 412)

Eine Begründung für diese Modifikation stellen sicherlich ähnliche Überlegungen dar, wie sie sich schon bei Shoemaker finden: es scheint viel plausibler, dem visuellen Gesichtsfeld genuine Farbeigenschaften zuzusprechen, da dieses nicht zu dem mentalen Wahrnehmungszustand selbst dazugehört und auch sonst keinen mentalen Charakter zu zeigen scheint; und zudem stellt sich das Problem mit der Introspektivität nicht unbedingt, weil unter der Voraussetzung von diesen sinnlichen Eigenschaften, welche den Sinnesdaten sehr ähnlich sind, eine Art von Wahrnehmungsmodell für Introspektion vielleicht aufrechterhalten werden kann (vgl. Shoemaker (1994a): 215). Damit ergibt sich die folgende Bestimmung des Wörtlichen Projektivismus: ${ }^{24}$

\section{(WP $\left.P_{\mathrm{SE}}\right) \quad P_{\mathrm{i}}:=F_{\mathrm{i}}$-phänomenale, von Regionen des visuellen Gesichtsfeldes instantiierte sinnliche Eigenschaft (sensational properties).}

Es stellt sich nun natürlich die Frage, wie das visuelle Gesichtsfeld im Subjekt realisiert ist. In dem allgemeinen Abschnitt über den Subjektivismus sind bereits die drei Möglichkeiten genannt und behandelt worden. Als Realisatoren für das Gesichtsfeld - das heißt: als Träger der subjektiven Farbeigenschaften - kommen drei Kandidaten in Frage: mentale Zustände, cerebrale Zustände und Sinnesdaten. Die letzte Alternative kann von vorneherein ausgeschlossen werden. Doch oben ist ebenso argumentiert worden, daß auch die erste Variante nicht zutreffen kann. Farben als Eigenschaften von mentalen Zuständen anzusehen, die von den Farbwahrnehmungen distinkt sind, aber von diesen auf gewisse Weise präsentiert werden, bringt unweigerlich beträchtliche, epistemologische Schwierigkeiten mit sich. ${ }^{25}$ Denn es ist mehr als unplausibel, von einer zwischen mentalen $\mathrm{Zu}$ -

24 Boghossian und Velleman sind eindeutig Vertreter dieser Position, obwohl sie letztlich eine nicht-reduktive Analyse der Farben nicht ausschließen (vgl. Boghossian \& Velleman (1989): 96). Peacockes subjektivistischer Dispositionalismus zeigt ebenfalls sehr große Ähnlichkeit mit dieser Position.

25 Brian O'Shaughnessy (1986) scheint anzunehmen, daß es vor den Wahrnehmungen noch mentale, nicht-repräsentationale Farbempfindungen gibt, die die sinnli- 
ständen bestehenden Präsentationsrelation auszugehen, die weder inferentiell, noch introspektiv fundiert ist. Wahrnehmungen sind sozusagen direkt an der Schnittstelle zwischen visuellem System und Geist: alles, was sich „davor“ befindet ist, ist nicht mental. Das steht auch nicht im Widerspruch zu der Aussage, daß uns die sinnlichen Eigenschaften präsentiert werden, da es durchaus zu erwarten ist, daß uns Wahrnehmungen Zugang zu nicht-mentalen Eigenschaften verschaffen (ganz gleich, um welche Art von Zugang es sich dabei handelt - Präsentation oder Repräsentation -, oder wo diese Eigenschaften instantiiert sein sollen).

Will man nun das visuelle Gesichtsfeld nicht in den Bereich des Geistes aufnehmen und lehnt zusätzlich die anderen, quasi-dualistischen Varianten - eine Sinnesdatentheorie oder einen Adverbialismus - von vorneherein $\mathrm{ab}$, dann muß das visuelle Gesichtsfeld durch cerebrale Zustände realisiert werden. Der Wörtliche Projektivismus $\left(\mathrm{WP}_{\mathrm{SE}}\right)$ wird damit zu einer reduktionistischen Position; ${ }^{26}$ er soll im folgenden einer besonderen Kritik unterzogen werden. Er ist vor allem dem Vorwurf ausgesetzt, wenn nicht eine Sinnesdatentheorie zu erfordern, so doch wenigstens dieser sehr ähnlich zu sein und auch einiger ihrer wesentlichen Probleme zu teilen. Die sinnlichen Eigenschaften zeigen aus ontologischer Sicht genau dieselbe, wechselseitige Abhängigkeit von den Wahrnehmungen, wie Sinnesdaten es tun würden: in jeder Farbwahrnehmung - und nur dann - werden solche farb-phä-

chen Eigenschaften instantiieren, so daß die Wahrnehmungen diese auf die Welt projezieren können. Doch dies bringt in unweigerlich in den Verdacht eines Indirekten Realismus, zumal er den Empfindungen zugesteht, daß sie selbst wahrgenommen werden können (vgl. Peacocke (1983): 5, Fn. 2; vgl. auch K. Campbell (1993): 265). Zudem ist es fraglich, ob es solche mentalen Farbempfindungen ohne Repräsentationalität überhaupt geben kann. Es ist wohl besser, die Träger der sinnlichen Eigenschaften als nicht-mentale Zustände anzusehen.

26 Russell hat vermutlich, zu einer bestimmten Zeit, eine Position vertreten, derzufolge Sinnesdaten als Zustände des Gehirnes außerhalb des Geistes anzusehen sind (vgl. Armstrong (1968): 225f.). Eine ähnliche Ansicht über die projezierten Eigenschaften findet sich auch bei Hardin (vgl. Hardin (1986): 111f.). Doch da letzterer gegen Sinnesdaten oder ähnliche Zustände als Träger der Farben argumentiert, ist es wahrscheinlich, daß dieser ganz auf eine Instantiierung der Farben verzichtet und einen Bildlichen Projektivismus vertritt (vgl. Einleitung zu Byrne \& Hilbert (1997a): xx). Die Einordnung von Hardins Position erschwert sich dadurch, daß in seinem Buch über Farben keine klare, positive Theorie der Farben vertreten wird (vgl. K. Campbell (1993): Fn. 8). 
nomenalen Eigenschaften präsentiert und liegen demnach auch nur genau dann im Subjekt instantiiert vor. Doch eine solche, strikte Korrelation kann weder die Sinnesdatentheorie, noch der reduktionistische Wörtiche Projektivismus annehmen, wie die Argumente gegen den Indirekten Realismus zeigen (vgl. etwa die farb-spezifischen Argumente in Hardin (1988): 96108).

Zudem liegt der Verdacht nahe, daß es sich bei den Farbeigenschaften der fraglichen Gehirnzustände letztlich doch um objektive Charakteristika handeln wird. Die Besprechung der relationalistischen Subjektivismen hat gezeigt, daß subjektive Farben nicht Eigenschaften externer, physikalischer Gegenstände sein können. Es ist gut möglich, daß Vergleichbares auch für interne, physikalische (das heißt: nicht-mentale) Zustände als vorgeschlagene Farbträger gilt. Dies wird auf alle Fälle dann sein, wenn die wechselseitige, ontologische Abhängigkeit aufgeben wird. Dann bestände zwar nicht mehr das Problem mit der Nähe zur Sinnesdatentheorie, aber dafür läge auch kein Subjektivismus mehr vor. Der entscheidende Punkt ist damit ganz einfach der, daß der reduktionistische Wörtliche Projektivismus entweder eine indirekt-realistische Theorie darstellen wird, oder aber den Farben doch einen objektiven Charakter zuzuerkennen muß. Russell, der ebenfalls die Schwierigkeiten der ersteren Alternative gesehen und ihn ausweichen wollte, hat wohl einmal die letztere Alternative in Betracht gezogen. Die resultierende Position bringt jedoch auf eine gewisse Weise das Schema der Unterscheidung von objektivistischen und subjektivistischen Theorien durcheinander.

„However, there is a complication here because there have been philosophers who believed that sense-data can exist unsensed - that there can be, in Russell's phrase, 'unsensed sensibilia'.

To spell the complication out. Suppose that a philosopher (i) holds that there are, or can be, unsensed sensibilia, that is, sense-data that are not 'in the mind'; (ii) does not identify sense-data with anything that we are ordinarily said to perceive, such as physical objects or the surfaces of physical objects; (iii) believes that the secondary qualities qualify sense-data. Russell seems to have held this conjunction of views at one time. He thougth of the sense-data as states of the perceiver's central nervous system, but as external to the perceiver's mind. (See D. F. Pears Bertrand Russell and the British Tradition in Philosophy, Fontana Library, 1967, Ch. III). Shoudl we call such a view 'Subjectivist'? Here it will be convenient 
(although it is not mandatory) to treat it as a form of Subjectivism." (Armstrong (1968b): 225f.)

Dies ist im Grunde die einzig denkbare Theorie, die für Farben das Merkmal der Objektivität fordert und das Merkmal der Externalität (im Sinne von „,vor den Augen“ oder ,an den Objekten“) ablehnt. Daß dieser Objektivismus sehr unplausibel ist, läßt sich einfach zeigen. Als ein Objektivismus, der die wechselseitige, ontologische Abhängigkeit aufgibt, wird er eine Repräsentationsrelation (oder eventuell bloß eine Detektionsrelation) zwischen Farbwahrnehmungen und Farbtatsachen annehmen müssen, um den epistemischen Zugriff erklären zu können. Doch damit sind alle die bereits erwähnten Probleme verbunden, die ein zweiter, repräsentationaler Gehalt mit sich bringt (wie etwa die Überdetermination der Erklärung, das Fehlen von Normalbedingungen und das unklare Verhältnis der beiden Gehalte untereinander). Zudem muß auch dieser Objektivismus von der Projektion von Farben auf die Außenwelt ausgehen. Und schließlich ist es alles andere als klar, was es heißt, daß Gehirnzustände wirklich Farbeigenschaften instantiieren. Somit hat diese Position keinen nennenswerten Vorteil gegenüber den projektivistischen Subjektivismen; und will man die Repräsentiertheit der Farben retten, ist der ,externe“ Objektivismus wesentlich plausibler.

Somit ist der Wörtliche Projektivismus doch gezwungen, eine auf wechselseitiger Abhängigkeit beruhende Präsentationsrelation anzunehmen, wie sie der Indirekte Realismus aufgrund seiner Akzeptanz der Aktualismusthese (AT) und seiner Ablehnung der Objektivitätsthese (OT) postuliert: Farbtatsachen liegen im visuellen Feld nur genau dann vor, wenn sie gerade in Farbwahrnehmungen präsentiert werden. Und um die mit der Sinnesdatentheorie verbundenen Probleme umgehen zu können, bleibt dem Wörtlichen Projektivismus nichts anderes übrig, als die Distinktheit von Farbwahrnehmung und Farbträger aufzugeben. Damit kommt Peacockes ursprüngliche, ontologische Interpretation der sinnlichen Eigenschaften (oder sensational properties) wieder zum Tragen, und die These $\left(\mathrm{WP}_{\mathrm{SE}}\right)$ reduziert sich auf die These $\left(\mathrm{WP}_{\mathrm{Q}}\right)$ : subjektive Farben sind identisch mit den Farbqualia. Dies kommt auch unseren Intuitionen am nächsten, denen zufolge das „Gesichtsfeld“ anscheinend doch auf die eine oder andere Weise zu den mentalen Wahrnehmungen ,gehört“. Doch wie die reduktionistische 
Position sieht sich, wie oben erläutert, auch der vermittels $\left(\mathrm{WP}_{\mathrm{Q}}\right)$ formulierte Wörtliche Projektivismus erheblichen Schwierigkeiten gegenüber. Vor dem Hintergrund dieser Überlegungen ist es sehr einleuchtend, warum so viele Subjektivisten den eliminativen Bildlichen Projektivismus der Wörtlichen Variante vorziehen, die Farben als mentale Eigenschaften auffassen möchte.

Es gibt jedoch noch zwei weitere Einwände gegen den Wörtlichen Projektivismus in seiner reduktionistisch verstandenden Form $\left(\mathrm{WP}_{\mathrm{SE}}\right)$. Zum einen ist es unklar, wie die cerebralen Zustände die Farbphänomenalität realisieren können sollen, insbesondere, wenn die physikalischen Reflektanzeigenschaften der Objekte in der Außenwelt dies nicht zu schaffen scheinen. Und zum anderen läßt sich auch hier gegen die Reduktion auf interne, physikalische Tatsachen ein Inversionsargument formulieren (vgl. K. Campbell (1993): 266). Denn es ist durchaus vorstellbar (wie auch schon im Abschnitt über die Notwendigkeitsthese besprochen), daß die durch die Gegenfarbtheorie postulierten chromatischen Informationskanäle ihre Kodierungen vertauschen: während $L-M$ nun das Gelb-Blau-Signal angibt, wird das Rot-Grün-Signal mittels $(L+M)-S$ kodiert. Doch dann kann ein- und dieselbe cerebrale Beschaffenheit sowohl eine rot-phänomenale als auch eine gelb-phänomenale Region im visuellen Gesichtsfeld realisieren, und verschiedene, cerebrale Beschaffenheit ein- und dieselbe Farbphänomenalität: so daß diese multipel realisierbaren, sinnlichen Eigenschaften des visuellen Gesichtsfeldes sich nicht mehr auf die neuronalen Beschaffenheiten reduzieren lassen. Als alternative, aber unplausible Instanzen der Farben bleiben somit nur mentale Zustände oder Sinnesdaten übrig - oder eben der vollständige Verzicht auf die faktische Existenz solcher Farbträger.

\subsubsection{Der Bildliche Projektivismus}

Diese Variante des Projektivismus macht es sich auf gewisse Weise sehr einfach, da sie die faktische Existenz sowohl von externen als auch von internen Farbtatsachen ablehnt. Es liegt somit ein Irrealismus oder non-factualism hinsichtlich der Farbeigenschaften vor: sie werden aus der aktualen Welt „eliminiert“. Der Bildliche Projektivismus (figurative projectivism) 
wird dabei wohl nicht so weit gehen und die Möglichkeit ausschließen, daß unter ganz anderen, vorherrschenden Naturgesetzmäßigkeiten nicht doch vielleicht Farben, so wie sie uns erscheinen, instantiiert sein könnten; zumindest enthält die Intuitive Farbkonzeption keinen offensichtlichen, logischen Widerspruch, der solch eine Exemplifizierung gänzlich unmöglich machen würde (wie etwa im Fall eines ,runden Quadrates“). Doch innerhalb der aktualen Welt - das heißt: unter den bestehenden NaturgesetzmäBigkeiten und der Beschaffenheit der existierenden, farbwahrnehmenden Subjekte - kann es überhaupt keine Farben geben.

Dadurch, daß er die Existenz von Farbtatsachen ganz leugnet, umgeht der Bildliche Projektivismus die problematische, ontologische Abhängigkeit der Farbwahrnehmungen von Farbtatsachen. Das umgekehrte Abhängigkeitsverhältnis bleibt natürlich bestehen. In diesem Sinne kann er auch weiterhin als Subjektivismus gelten. Denn gäbe es Farbtatsachen, wären sie geist-abhängig: sie beständen immer nur im Zusammenhang mit faktisch auftretenden Farbwahrnehmungen. Jedenfalls können Farben laut Bildlichem Projektivismus weder mit den Farbqualia, noch mit den postulierten, sinnlichen Eigenschaften des visuellen Gesichtsfeldes identifiziert werden. Diese Entscheidung wird auch durch die eben dargestellte Argumentation motiviert: es ist nicht möglich, subjektive, phänomenale Eigenschaften zu identifizieren, die uns in unseren Farbwahrnehmungen präsentiert werden können, ohne von diesen selbst instantiiert zu sein. Nur der Wörtliche Projektivismus in der Variante $\left(\mathrm{WP}_{\mathrm{Q}}\right)$ kann wenigstens einige Plausibilität genießen. Doch auch die Option, Farben mit den Farbqualia gleichzusetzen, ist nicht allzu vielversprechend.

„[Figurative projectivism] concedes that qualia, understood as properties of experiences, are not properties that could even seem to us to be instantiated in the world in the way in which colors, for example, are perceived as being. But it says that associated with each quale is a property that can seem to us to be instantiated in the world in this way - and that when an experience instantiates a quale, the subject perceives something in the world as instantiating, not that quale itself, but the associated property. The property is in fact not instantiated in the external objects, or in any other object - its seeming to be instantiated there is a result of how the perceiver is constituted. That is what makes the view projectivist. But the property also is not instantiated in the experiences of the perceiver - that is what makes the projectivism figurative.“ (Shoemaker (1994b): 231) 
Was diese fraglichen Eigenschaften wirklich sind, kann nicht weiter gesagt werden. Denn für eine ontologische Untersuchung derselben wäre es erforderlich, daß sie irgendwo instantiiert wären. In diesem Sinne existieren die Farben faktisch nur in den Erscheinungen der farbwahrnehmenden Subjekte, niemals jedoch in der Realität selbst (einschließlich des Subjektes selbst). Trotzdem kann mithilfe der Thesen ( $\mathrm{IND}_{\mathrm{P}}$ ) und (PHE) eine Analyse der Natur der Farben vorgenommen werden: Eigenschaften müßten genau diese phänomenalen Merkmale und Beziehungen zeigen, um tatsächlich als Farben gelten zu können. In dem Abschnitt über den Wörtlichen Projektivismus sind bereits die Kandidaten für diese Bedingung untersucht und - bis vielleicht auf die Farbqualia der Wahrnehmungen selbst - als nicht angemessen zurückgewiesen worden. Der Bildliche Projektivismus zieht hieraus die Konsequenz, daß es solche mit einer Farbphänomenalität in unseren Sinneserfahrungen gegebenen Eigenschaften nicht instantiiert geben kann. Er läßt sich somit ganz einfach wie folgt bestimmt werden: ${ }^{27}$

(BP) $\quad P_{\mathrm{i}}:=$ in Farbwahrnehmungen phänomenal präsentierte, faktisch aber nicht instantiierte Eigenschaften.

Der Bildliche Projektivismus kann jedoch auch durch eine andere, unnach-

27 Vertreten wird diese Position von Mackie (vgl. (1976): 11) und - sehr wahrscheinlich - von Hardin (vgl. (1988): 112). Maund (1995) ist ebenfalls ein Anhänger des Bildlichen Projektivismus (vgl. Einleitung zu Byrne \& Hilbert (1997a): xx), genauso wie Hume nach Barry Strouds Interpretation (vgl. Shoemaker (1990): 116). - Wright schließlich scheint vermutlich ebenfalls eine ähnliche Position aufzuweisen. Doch dies ist schwierig einzuschätzen, da seine Überlegungen zu der Farbproblematik rein epistemologischer, und nicht ontologischer, Natur sind (Wright (1988); Wright (1992): 108-139). Der Grund hierfür ist, daß Wright einen robusten, realistischen Wahrheitsbegriff aufgibt und ihn (zumindest für bestimmte Diskurse) durch einen epistemologisch bestimmten ersetzt. Dahinter verbirgt sich die Idee eines Anti-Realismus hinsichtlich von Bedeutungen von Aussagen und Meinungen (innerhalb der fraglichen Diskurse vgl. Wright (1992): Kap. 2; sowie Boghossian (1989)). Seine Ausführungen sind für die hier - vor dem Hintergrund eines globalen Realismus mit einem robusten Wahrheitsbegriff - angestellten Betrachtungen zur Ontologie der Farben jedoch nicht von besonderem Interesse, zumal dieses Buch sich allein auf Farbwahrnehmungen konzentriert und Farburteile nicht miteinbezieht. 
giebigere Auffassung von Farben motiviert werden. Es kann durchaus sein, daß jemand die Transparenzthese (TT) in ihrer vollen Stärke erhalten möchte. Zeigt es sich nun aber, daß der dafür erforderliche Objektivismus $_{\mathrm{NEC}}$ nicht der Realität entspricht, bleibt dem Betreffenden nichts anderes übrig, als die Existenz von Farbtatsachen ganz zu leugnen. Im Grunde müßte er dann auch eine projektivistische Erklärung für das Auftreten der Farbphänomenalität in unseren Sinneserfahrungen geben. Interessanterweise wird auch der Objektivismus ${ }_{\mathrm{ACT}} \mathrm{zu}$ einem solchen Projektivismus gezwungen sein. Letzterer unterscheidet sich jedoch von der subjektivistischen Variante dadurch, daß er nicht davon ausgeht, daß es die Farbigkeit ist, die auf die Welt projeziert wird. Auf die damit verbundenen Probleme wird jedoch erst später genauer eingegangen werden. Für den Moment genügt es, sich auf die Schwierigkeiten des Bildlichen Projektivismus zu konzentrieren, die zumindest zu einer wesentlichen Modifikation der bisher vorgestellten Theorie führen, welche das Verhältnis zwischen Farben und Farbqualia verstehen helfen wird.

Das Hauptproblem für den Bildlichen Projektivisten ist es, zu erklären, wie es kommen kann, daß uns nicht instantiierte Eigenschaften durch Farb wahrnehmungen sinnlich, und auch introspektiv, gegeben sein können. Denn wenn Farben faktisch niemals extern oder intern exemplifiziert waren oder sind, ist es fraglich, wie wir überhaupt epistemischen Zugang zu ihnen und ihrer Natur haben können. Der einzige Ausweg scheint wohl der zu sein, daß man eine Art von „Gegebenheitsweise“ annimmt, mit deren Hilfe Farben uns in Sinneserfahrungen präsentiert werden können, ohne daß sie selbst dabei instantiiert sein müssen (zu dieser Argumentation vgl. Shoemaker (1990): 117f.). ${ }^{28}$ Diese Rolle können nun die Farbqualia über-

28 Innerhalb der Ausführungen Shoemakers sind die Ausdrücke „Gegebenheitsweise“ oder auch „Sinn“ angemessener, da er von einem zweiten, repräsentationalen Gehalt der Farbwahrnehmungen ausgeht, welcher eine Farbeigenschaft beinhaltet. Diese Redeweise trifft, wie gesagt, jedoch nur bedingt zu, weil Farben nicht repräsentierte, sondern allein präsentierte Eigenschaften sein können. Demgemäß kann hier nicht von genuinen Gegebenheitsweisen die Rede sein, sondern nur Bezug genommen werden auf das spezielle Verhältnis zwischen den Farben und den Farbqualia: daß die Postulation ersterer erst letztere zu Farbqualia macht, und die entsprechenden Wahrnehmungen zu Farbwahrnehmungen; und daß damit unweigerlich verbunden ist, daß die Phänomenalität der (wenn auch nicht instantiierten) Farben mit dem phänomenalen Charakter der fraglichen Sinneser- 
nehmen, deren Phänomenalität mit der Phänomenalität der Farben übereinstimmt. Man erinnere sich auch daran, daß phänomenale Farbwahrnehmungstypen ja laut Projektivismus gerade über Farben definiert werden: so ist es zu erwarten, daß der phänomenale Charakter der Wahrnehmungen von der Phänomenalität der Farben entsprechen muß oder sogar von ihr bestimmt wird. Während der Wörtliche Projektivismus $\left(\mathrm{WP}_{\mathrm{Q}}\right)$ Farben mit den Farbqualia identifiziert, beschreibt der Bildliche Projektivismus das Verhältnis der beiden Eigenschaften anders. Die Qualia fungieren als „Gegebenheitsweisen“, mit deren Hilfe die Farben uns phänomenal präsentiert werden - ganz gleich, ob es diese wirklich gibt oder nicht.

Zudem kann nun auch eine einfache Erklärung der Beziehung zwischen den Farben und den repräsentierten Eigenschaften gegeben werden. Denn hinsichtlich der wahrgenommenen, objektiven Eigenschaften der Gegenstände in der Außenwelt können die Farbqualia genuine Gegebenheitsweisen darstellen (jedoch ohne die Gültigkeit des Prinzipes sense determines reference). Dies ist sogar erforderlich, wenn jemand die Möglichkeit von Inversionsbeispielen behauptet und die Notwendigkeitsthese (NEC) ablehnt (un ein Subjektivismus, der dies nicht tut, hat gegenüber dem Objektivismus $_{\mathrm{NEC}}$ kaum einen Vorteil). Denn in solchen Fällen können die externen Tatsachen nicht unmittelbar transparent gegeben sein, sondern müssen durch die in den Sinneserfahrungen präsentierten Eigenschaften vermittelt werden (ein Gegenstand, der zum Beispiel für die eine Person rot aussieht, wird von einer anderen als grün wahrgenommen). Der allgemeine Gehalt einer Farbwahrnehmung ist uns dann introspektiv allein über das Quale zugänglich; und letzteres kann dabei nicht über ersteres erklärt werden (vgl. Abschnitt über Qualia; und Shoemaker (1990): 103f.). Da die projektivistisch verstandenden Farben die Phänomenalität der Farbqualia vorgeben in dem Sinne, daß die Wahrnehmungen mit den fraglichen Qualia erst durch diesen Bezug zu (wenn auch nur postulierten) Farbeigenschaften als Farbwahrnehmungen gelten -, und da die Qualia als genuine Gegebenheitsweisen für die repräsentierten Eigenschaften in der Welt fungieren, kann somit ohne weiteres davon gesprochen werden, daß die Farben (oder die Farbphänomenalität) auf die Realität projeziert wird.

Doch damit ist eine Verdoppelung der Fehlerhaftigkeit der Projektion verbunden. Der Wörtliche Projektivismus muß bereits einen systemati-

fahrungen übereinstimmt. 
schen Fehler hinsichtlich des repräsentationalen Aspektes des introspektiven Charakters von Farbwahrnehmungen zugestehen: ganz im Gegensatz zu ihrem Erscheinungsbild sind die in den betreffenden Sinneserfahrungen präsentierten Eigenschaften nicht repräsentierte und von Objekten in der Außenwelt instantiierte Merkmale. Darüberhinaus ist der Bildliche Projektivismus nun gezwungen, noch einen weiteren, systematischen Fehler hinsichtlich der Existenz von Farbtatsachen hinzunehmen: fälschlicherweise halten wir die Farbqualia, mit deren Hilfe die Phänomenalität der Farben auf die Welt projeziert wird, für die Farbeigenschaften selbst. Denn es ist uns keineswegs offensichtlich, daß die in Farbwahrnehmungen präsentierten Farben in Wirklichkeit gar nicht instantiiert sind. Somit sind die beiden Überzeugungen, daß einerseits Farben eine repräsentationale Natur haben und daß andererseits Farbtatsachen faktisch existieren, gleichermaßen Bestandteile unseres gewöhnlichen Verständnisses über Farben, die nicht auf die Realität zutreffen. Daß der Wörtliche Projektivismus nur einen systematischen Fehler erster Art aufweist, ist zumindest ein Grund, zu erwägen, ihm der Bildlichen Variante vorzuziehen.

„According to this view, the experience of the world as coloured involves a
double mistake. In the first place, no colour is a physical property of the environ-
ment; contrary to how things seem, objects in the outer world would not be col-
oured were there no perceivers with colour vision. (Objectivism is false). In the
second place, no sense data - or visual field patches understood as psychological
states of perceivers - are coloured either. (Subjectivism in the Lockean tradition
is false.) [...] Projection is the first error. Experiencing what is projected as yel-
low, or turquoise, or whatever, is the second. There are no colours. Here we have
a desperation option indeed.“ (K. Campbell (1993): 266f.)

Dieser Nachteil gegenüber den anderen Theorien der Farben muß jedoch nicht unbedingt gegen den Bildlichen Projektivismus sprechen, da auch die alternativen Positionen ihre Mängel aufweisen. Aber er weist auf den Umstand hin, daß die eliminative Analyse im Grunde erst der allerletzte Versuch sein sollte, die Individuationsthese (IND) aufrechtzuerhalten. Shoemaker hat zudem noch darüber hinausgehende Zweifel an der Plausibilität dieser radikalen, subjektivistischen Position. 
„In addition, while we can make sense of the idea of there being properties that are in some way represented in our experience but never instantiated in anything - e.g., the property of being a ghost - it is difficult, to say the least, to make sense of the idea that experienced color could be such a property. Granted that there are in fact no ghosts, we at least have some idea of what would count as someone veridically perceiving an instantiation of the property of being a ghost. But if we ourselves do not count as veridically perceiving the instantiation of redness-aswe-experience-it, I think we have no notion of what would count as veridically perceiving this.“(Shoemaker (1994b): 232)

Wird dieser Einwand so verstanden, daß der Projektivist nicht angeben kann, wie eine interne Farbtatsache beschaffen sein müßte, um als zutreffend präsentiert zu gelten, dann stellt er nicht wirklich eine Schwierigkeit dar, da die Farben ja vermittels der Farbqualia präsentiert werden und somit deren Phänomenalität entsprechen müssen. Doch Shoemaker hat hier wohl den zweiten, systematischen Fehler - daß die auf die Welt projezierten Eigenschaften fälschlicherweise als instantiierte Farben angesehen werden - gar nicht im Sinn, sondern vielmehr den ersten, demzufolge die farbphänomenalen Qualia der mentalen Wahrnehmungen auf die Realität projeziert werden. Dahinter verbirgt sich erneut der Vorwurf, daß der Projektion ein kategorialer Fehler zugrundeliegt: daß die externen Objekte als Träger von mentalen Eigenschaften präsentiert werden, die sie ganz prinzipiell nicht instantiieren können. Und es weitaus schwieriger, sich vorzustellen, daß unsere visuellen Sinneserfahrungen einer solchen Verwechslung von Kategorien verfallen sollten. Der Bildliche Projektivismus ist somit - genauso wie der über $\left(\mathrm{WP}_{\mathrm{Q}}\right)$ definierte Wörtliche Projektivismus - eine mögliche Theorie der Farben, deren Plausibilität sich jedoch in Grenzen hält und die dementsprechend nur als ein letzter Ausweg angesehen werden sollte. 
